\section{Light-driven post-translational installation of reactive protein side} chains

Brian Josephson ${ }^{1,7}$, Charlie Feh ${ }^{1,5,7}$, Patrick G. Isenegger ${ }^{1,7}$, Simon Nadal ${ }^{1}$, Tom H. Wright ${ }^{1,6}$, Adeline W. J. Poh $^{1}$, Ben J. Bower ${ }^{1}$, Andrew M. Giltrap ${ }^{1}$, Lifu Chen ${ }^{2}$, Christopher Batchelor-McAuley ${ }^{2}$, Grace Roper ${ }^{1}$, Oluwatobi Arisa ${ }^{1}$, Jeroen B. I. Sap ${ }^{1}$, Akane Kawamura ${ }^{1}$, Andrew Baldwin ${ }^{1}$, Shabaz Mohammed ${ }^{1,3}$, Richard G. Compton $^{2}$, Veronique Gouverneur ${ }^{1} \uparrow \&$ Benjamin G. Davis ${ }^{1,4} \dagger$

${ }^{1}$ Chemistry Research Laboratory, Department of Chemistry, University of Oxford, Oxford, UK.

${ }^{2}$ Physical and Theoretical Chemistry Laboratory, Department of Chemistry, University of Oxford, Oxford, UK ${ }^{3}$ Department of Biochemistry, University of Oxford, Oxford, UK.

${ }^{4}$ The Rosalind Franklin Institute, Didcot, UK.

${ }^{5}$ Present address: Department of Chemistry, Wayne State University, USA

${ }^{6}$ Present address: Department of Molecular Biology, Massachusetts General Hospital, USA.

${ }^{7}$ These authors contributed equally: Brian Josephson, Charlie Fehl, Patrick G. Isenegger.

†e-mail: veronique.gouverneur@chem.ox.ac.uk; ben.davis@chem.ox.ac.uk; ben.davis@rfi.ac.uk

Post-translational modifications (PTMs) greatly expand the structures and functions of proteins in nature ${ }^{1,2}$. Although synthetic protein functionalization strategies allow mimicry of PTMs ${ }^{3,4}$, as well as formation of unnatural protein variants with diverse potential functions, including drug carrying ${ }^{5}$, tracking, imaging ${ }^{6}$ and partner crosslinking ${ }^{7}$, the range of functional groups that can be introduced remains limited. Here we describe the visible-light-driven installation of side chains at dehydroalanine residues in proteins through the formation of carbon radicals that allow $\mathrm{C}-\mathrm{C}$ bond formation in water. Control of the reaction redox allows site-selective modification with good conversion efficiencies and reduced protein damage. In situ generation of boronic acid catechol ester derivatives generates $\mathrm{RH}_{2} \mathrm{C}^{\cdot}$ radicals that form the native $\left(\beta-\mathrm{CH}_{2}-\gamma\right.$ $\mathrm{CH}_{2}$ ) linkage of natural residues and PTMs, whereas in situ potentiation of

pyridylsulfonyl derivatives by $\mathrm{Fe}(\mathrm{II})$ generates $\mathrm{RF}_{2} \mathrm{C}^{\cdot}$ radicals that form equivalent $\beta$ $\mathrm{CH}_{2}-\gamma-\mathrm{CF}_{2}$ linkages bearing difluoromethylene labels. These reactions are chemically tolerant and incorporate a wide range of functionalities (more than $\mathbf{5 0}$ unique residues/side chains) into diverse protein scaffolds and sites. Initiation can be applied chemoselectively in the presence of sensitive groups in the radical precursors, enabling installation of previously incompatible side chains. The resulting protein function and reactivity are used to install radical precursors for homolytic on-protein radical generation; to study enzyme function with natural, unnatural and $\mathrm{CF}_{2}$-labelled posttranslationally modified protein substrates via simultaneous sensing of both chemo- and stereoselectivity; and to create generalized 'alkylator proteins' with a spectrum of heterolytic covalent-bond-forming activity (that is, reacting diversely with small molecules at one extreme or selectively with protein targets through good mimicry at the other). Post-translational access to such reactions and chemical groups on proteins could be useful in both revealing and creating protein function.

Methods that use the translational machinery of the cell provide powerful advantages for installing selected modifications into proteins, but can be limited in scope and efficiency ${ }^{8-10}$. Unnatural amino acid precursors fed into the cell can be degraded or may not be tolerated during biosynthesis; this is especially true for those with reactive side chains ${ }^{11}$. Posttranslational functionalization ${ }^{12-16}$ offers an alternative strategy that, through its late-stage use, could be broader in scope; in principle, it is only limited by the compatibility of the reaction conditions used with the protein substrate and its context.

In one version ${ }^{12-15,17}$ of post-translational functionalization, a readily generated dehydroalanine (Dha) residue is used in proteins as a singly occupied molecular orbital (SOMO) acceptor ('radical acceptor' or 'SOMO-phile') that is highly reactive towards several carbon radical species, thereby allowing selective $\beta, \gamma-\mathrm{C}-\mathrm{C}$ bond formation to introduce new side chains in a 'scarless'/'traceless' manner (Extended Data Fig. 1). However, incompatibilities of side-chain/carbon radical precursors and the reagents that generate them (for example, single-electron transfer from metals or $\left.\mathrm{BH}_{4}^{-}\right)^{14,15}$ currently limit scope. Nonetheless, such homolytic single-electron $\left(1 e^{-}\right)$chemistry has potential advantages over typical heterolytic two-electron $\left(2 e^{-}\right)$reagents. The intrinsic challenges ${ }^{18}$ of biomolecule modification include: water compatibility; requirement for 'benign-ness'; and low (or non-) reactivity towards a plethora of biogenic acids, amines, alcohols and thiols (ready $2 e$ reactants) that are present in most biological environments (Extended Data Fig. 1a). By contrast, water and native proteins are less reactive to most ${ }^{19}$ carbon radicals; therefore, suitably placed SOMOphiles such as Dha can allow more general chemo- and site-selectivity in certain $1 e^{-}$chemistries (Extended Data Fig. 1b)

Other methods for single-electron transfer (and hence carbon radical initiation, oxidative or reductive) exist. Catalytic protein methods bring clear advantages ${ }^{20}$ over prior super-stoichiometric methods (which can drive unwanted side reactions; Extended Data Fig 1c-e). Furthermore, if regulated by a relatively benign, potentially tissue-penetrating trigger 
such as light ${ }^{21}$, it could allow additional layers of, for example, temporal, spatial and even kinetic control to complement those of $1 e^{-}$chemoselectivity. Light-stimulated outer-sphere electron transfer has seen a resurgence in applications to small molecules ${ }^{22,23}$. However, its use in site-selective, biomolecule modification has been more limited. Leading examples (Extended Data Fig. 1d, e and Supplementary Discussion 1) have largely been restricted to peptides ${ }^{24-26}$, sometimes requiring mixed organic solvents ${ }^{26}$ and/or electron-transfer systems that sit towards the extremes of redox 'windows', and resulting side reactions have been observed $^{25}$. Moreover, dependence on certain precursor moieties, such as $\alpha$-C-carboxy $1^{24}$ or $\beta-\mathrm{C}-\mathrm{H}\left(\right.$ ref. ${ }^{25}$ ), that cannot be re-/pre-positioned, can limit the reaction site and/or lead to lower site-selectivity owing to abundance. These methods have therefore yet to reach their full potential in protein chemistry.

Here, we show that a combination of (i) electron transfer at benign, moderate redox potentials using (ii) side-chain carbon radical precursors 'redox-matched' with low, even substoichiometric, amounts of photocatalyst, triggered by (iii) light of appropriate flux, allows the generation and use of both off-protein and on-protein radicals to modify proteins via $\mathrm{C}-\mathrm{C}$ bond formation (Fig. 1).

\section{Results}

\section{Photocatalytic carbon radical protein modification}

Exploitation of the carbon radical could involve either off- or on-protein radicals with reductive or oxidative initiation. A pre-positioned on-protein SOMO-phile, such as Dha, allows the flexibility of off-protein carbon radical generation by either method (Fig. 1, Extended Data Fig. 2). Initial scoping with photocatalysts covering a wide redox spectrum (Extended Data Fig. 2a) under varying aqueous reaction conditions (aerobic/anaerobic, pH, co-solvent, redox mediators, light flux) avoided the use of organic co-solvents or extremes of $\mathrm{pH}$, because these are incompatible with many full-length proteins (see Supplementary Discussion 1, Supplementary Tables 1-3 and Extended Data Fig. 3a, b). These revealed: (a) an effectiveness of catechol beyond hydrogen atom $\operatorname{transfer}^{27}$ (as noted previously for organosilicates ${ }^{28}$ ) in oxidative activation of alkyl organoboronates and (b) a relative ineffectiveness of alkylhalides as reductive precursors. Both observations suggested avenues for improvement.

The potentiation of (and activation of previously unreactive) alkyl boronates by catechol using low- $* E_{\mathrm{ox}} /{ } E_{\text {red }}$ catalysts was surprising, because $* E_{\mathrm{ox}-\text { catalyst }}>E_{\mathrm{ox} \text {-substrate }}$ typically determines reactivity. Primary $\mathrm{C}-\mathrm{B}$ bonds $(\geq+1.5 \mathrm{~V})$ were previously inaccessible However, with catechol, even the challenging substrate $\mathrm{PhCH}_{2} \mathrm{CH}_{2}-\mathrm{BF}_{3} \mathrm{~K}\left(E_{\mathrm{ox}}>+1.6 \mathrm{~V}\right)$ proved to be reactive not only with $\mathbf{C a t} 3\left({ }^{*} E_{\mathrm{ox}}=+1.32 \mathrm{~V}\right)$ and $\mathbf{C a t} 4(\mathrm{Ru}(\mathrm{bpz}) ;$; $\left.{ }^{*} E_{\mathrm{ox}}=+1.45 \mathrm{~V}\right)$, but also with the much weaker catalysts Cat1 $\left.(\mathrm{Ru}(\mathrm{bpy}))_{3} ;{ }^{*} E_{\mathrm{ox}}=+0.77 \mathrm{~V}\right)$ and Cat2 $\left(\mathrm{Ru}(\mathrm{bpm})_{3},{ }^{*} E_{\mathrm{ox}}=+0.99 \mathrm{~V}\right)$. These milder catalysts gave enhanced conversion efficiencies: for example, $>90 \%$ H3-homohomoPhe9 (H3-1h; see Extended Data Fig. 8 for side-chain glossary) from H3-Dha9.

The action of catechol was inconsistent with $\mathrm{HAT}^{27}$ (Extended Data Fig. 3a and Supplementary Table 4). We tested three mechanistic possibilities (Extended Data Fig. 4 and Supplementary Discussion 2): mediated electron transfer, catalyst modification and substrate modification. (During the course of this work, the beneficial effects of catechols were also independently observed in small-molecule systems; see ref. ${ }^{29}$.) First, from analogues and potential redox mediators (Extended Data Fig. 4a-c) only aromatic 1,2-vicinal diols potentiated. Second, the Ru complex ${ }^{30}$ from ligand-exchange catecholo-Ru(bpy)2-Cat 6 (Extended Data Fig. 4d) displayed no activity. Third, use of pre-formed boronic acid catechol esters revealed efficient conversion, even without exogenous catechol (Extended Data Fig. 4e, f). Moreover, cyclic voltammetry (Extended Data Fig. 4g-1 and Extended Data Fig. 2b inset) revealed a concentration-dependent, shifted boronate $E_{\text {ox }}$ that brought these carbon radical precursor substrates within range of the mild catalysts Cat1, Cat2 (see also Supplementary Discussion 3). Together, these data were consistent with in situ boronic acid catechol ester derivatives, termed BACED reagents (BACED, boronic acid catechol ester; Fig. 1, Extended Data Fig. 2c), allowing efficient oxidative side-chain carbon radical generation via turnover of catechol in aqueous medium (even at $2 \mathrm{~mol} \%$; Supplementary Table 5) and lowered photocatalyst loadings (for example, from 100 equiv. to $25 \mathrm{~mol} \%$ of Cat1; Supplementary Table 5) to rare ${ }^{20}$ substoichiometry.

Next, the failure in scoping simple alkylhalides as reductive carbon radical precursors suggested substrate modulation. $\alpha$-Fluoro substitution alters the stability and reactivity of the carbon radical ${ }^{31}$ and increases the addition reactivity in water $^{32} . \mathrm{H} \rightarrow \mathrm{F}$ variation migh therefore give enhanced $\mathrm{RF}_{2} \mathrm{C}^{*} / \mathrm{RFHC}^{*}$ as near-size ${ }^{33} \mathrm{RH}_{2} \mathrm{C}^{*}$ equivalents, with the potential to generate near-'zero-size' $\mathrm{H} \rightarrow \mathrm{F}$ labels in protein side chains. From various potential $\mathrm{RF}_{2} \mathrm{C}^{\text {' }}$ precursors ${ }^{34}$, scoping (Supplementary Discussion 4 ) revealed pySOO- $\mathrm{CF}_{2} \mathrm{R}$ pyridyl-sulfonefluorides (pySOOF) reagents with suitable $E_{\text {red }}$ (ref. ${ }^{35}$ ) and enhanced reactivity (in $15 \mathrm{~min}$ ) However, the initially observed products were consistent with partial, unwanted oxidative 
(instead of reductive) quenching of the resulting intermediate protein- $\alpha$-carbon radical to hemiaminal/imine (for example, only $58 \%$ conversion to H3-DfeGly9 from H3-Dha using pySOO- $\mathrm{CF}_{2} \mathrm{H}$; Extended Data Fig. 2d). Various reductive additives and HAT sources failed or led to other unwanted side reactions (Extended Data Fig. 5) but led us to consider direct electron transfer from metals (Extended Data Figs. 2d, 6); Zn(II) and Mn(II) gave no change and $\mathrm{Ni}$ (II) and $\mathrm{Cu}$ (II) inhibited the reaction, but $\mathrm{Fe}$ (II) sources (preferably Fe(II) sulfate) achieved good conversion ( $>92 \%$ to H3-DfeGly9; Extended Data Fig. 6). Notably, consistent

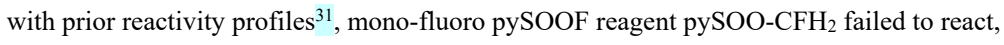
even under optimized conditions (Extended Data Fig. 7), but pySOOF reagents bearing additional carboxylate or acetamide groups (pySOO-CHFCOOH and pySOO-CHFC(O)NH generating side chains $2 \mathbf{s}$ and 2u , respectively; Extended Data Fig. 8) displayed high reactivities (with only 10-25 equiv. pySOOF; Extended Data Fig. 7). Together, these and other (Extended Data Fig. 7) data were consistent with dual reductive quenching and potentiation by $\mathrm{Fe}$ (II) allowing efficient reductive side-chain carbon radical generation and, again, rare substoichiometry, not only of the photocatalyst but also $\mathrm{Fe}$ (II) (for example, $25 \mathrm{~mol} \%$ Cat1, 50 mol $\% \mathrm{FeSO}_{4}$, 10 equiv. pySOOF, 66\% conversion; Supplementary Tables 8-22 and Extended Data Fig. 6).

\section{Optimization of BACED and pySOOF reagents}

Together, these mechanistic studies revealed mild, efficient complementary pathways using BACED or pySOOF reagents (Fig. 1), potentiated by catechol or Fe(II), respectively. The wide availability of boronic acids (directly as BACED reagents) or pyridylsulfones (allowing ready synthesis of pySOOF reagents; see Supplementary Methods) enabled rapid, broadscope optimization and application to introduce native and difluorinated amino acid side chains and/or side chains bearing post-translational modifications into proteins (Extended Data Fig. 8). Reaction times were shortened by investigating the light flux in a variableintensity photoreactor (Extended Data Fig. 3d); use of $50 \mathrm{~W}$ power and $\sim 450 \mathrm{~nm}$ wavelength reduced the reaction times (from typically $4 \mathrm{~h}$ to $<1 \mathrm{~h}$ for BACED and to $<15 \mathrm{~min}$ for pySOOF; Supplementary Tables 6, 18 and Extended Data Figs. 3d, 7). Photocatalyst matching also enhanced efficiency; for example, Cat1 proved superior for secondary and benzyl BACED and pySOOF reagents (Extended Data Figs. 3c, 6), whereas Cat2 better matched more difficult primary BACED reagents.

These optimizations enabled efficient light-controlled protein modification to the following set of general conditions. For BACED: protein $1 \mathrm{mg} \mathrm{ml}^{-1} ; 50 \mathrm{~W} 450 \mathrm{~nm}$ light; $4{ }^{\circ} \mathrm{C}$ to room temperature; 100-1,500 equiv. BACED precursor reagent; 10 equiv. Cat1 or Cat2;

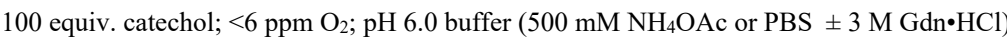
For pySOOF: protein $1 \mathrm{mg} \mathrm{ml}^{-1}$; $50 \mathrm{~W} 450 \mathrm{~nm}$ light; room temperature; $2-5$ equiv. pySOOF precursor reagent; $0.4-4$ equiv. Cat1; 50-100 equiv. $\mathrm{FeSO}_{4} ;<6$ ppm O $2 ;$ pH 6.0 buffer ( $500 \mathrm{mM} \mathrm{NH}_{4} \mathrm{OAc}$ or various other buffers). Both reactions proved readily scalable to $5 \mathrm{mg}$ protein levels (see Supplementary Methods). In all cases, control reactions under essentially identical conditions but in the absence of light or photocatalyst or catechol (for BACED) failed (Supplementary Tables 7, 16 and Extended Data Fig. 7). Sustained irradiation was also necessary, precluding chain mechanisms (Extended Data Figs. 3e, 7). It is striking that under these optimized conditions, even when using carbon radical precursor as a limiting reactant (instead of protein), good yields were still obtained: 0.5 equiv. of pySOO- $\mathrm{CF}_{2} \mathrm{H}$ gave $40 \%$ conversion ( $80 \%$ yield; Extended Data Fig. 6).

Diverse side chains inserted into proteins

In this way, a diverse range of side chains (Extended Data Fig. 8) were readily inserted through catalytic, light-driven, carbon radical-mediated $\mathrm{C}-\mathrm{C}$ bond formation into a range of representative protein scaffolds - - for example, mixed disordered/ $\alpha$-helix-rich $\mathrm{H} 3$ and $\mathrm{H} 4$, the enzyme PanC (mixed $\alpha-\beta$ two- or three-layered sandwich), $\mathrm{Np} \beta$ (pentapeptide $\beta$-sheet repeat), periplasmic protein AcrA ( $\alpha$-helix coiled coil), single-chain antibody cAbLys3 ( $\beta$ sheet CDRs)—and at different sites within scaffolds—-for example, H3-Dha4, -Dha9, -Dha18 and -Dha27 (Fig. 1).

Many side chains (Extended Data Fig. 8) were incompatible with previous methods for protein modification ${ }^{14,15}$, including olefins (1e, 1f), azides (1r, 2b, 2ac), halogens (1s, 1t, 1y, 1v, 1w, 2b, 2ad), sulfoxide/sulfones/sulfates (2y, 2z, 2aa, 2ae, 2af), esters (1p, 1q, 2m, 2n, 2r) and amides (peptidic, 1x; biotinyl, 1y, 2ag; and acyllysine derivatives, $1 \mathbf{m}, \mathbf{1 n}, \mathbf{1 y}$,

\section{2k, 2l, 2m, 2n, 2w, 2ag)}

For example, iodo-amides (precursors for acyllysines) are unstable with respect to cyclization ${ }^{15}$ under current reductive methods; yet here, BACED and pySOOF reagents allowed ready, intact installation. (In our work, the final step to such precursors typically yields $<1 \%$ of unstable product compared to literature reports ${ }^{36}$ of $<4 \%$; the corresponding boronate is readily prepared and used in excellent yield.) Reductively sensitive ${ }^{14}$ esters (1p $\mathbf{1 q}, \mathbf{2 m}, \mathbf{2 n}, \mathbf{2 r})$ and varied oxidation states of methionine $(\mathbf{2 x}, \mathbf{2 y}, \mathbf{2 z})$ were tolerated. Excellent compatibility and chemoselectivity were also seen for olefins $\mathbf{1 e}$ and $\mathbf{1 f}$ (well known radical 'traps' $)^{37}$ and known photoredox-sensitive azides ${ }^{38}$ - for example, into 
azidonorleucine (Anl) 1r, 2ab ( $\gamma \mathrm{CF}_{2}$-azidonorvaline) or $\mathbf{2 a c}\left(\gamma \mathrm{CF}_{2}\right.$-Anl)—allowing potentia for subsequent redox 'uncaging' or other azide reactions.

Such was the chemoselectivity, that we next tested use of carbon radical precursors bearing two competing (geminal or distal) groups for potential initiation. First, remarkably, halo-pySOOF reagents pySOO- $\mathrm{CF}_{2}-\mathrm{Hal}$ (Hal, halogen; Fig. 2a) could be chemoselectively activated to generate pySOO- $\mathrm{F}_{2} \mathrm{C}^{*}$ radicals that allowed installation of mono- and difluoropySOOF side chains (2ae, 2af) into proteins (Fig. 2a). Second, BACED and pySOOF reagents bearing two distal initiator groups allowed installation of a diverse range of sidechain halides (F, Cl, Br, I; Fig. 2b), either with short alkyl linkers to the protein backbone (1s $\mathbf{1 t}, \mathbf{1} \mathbf{u}, \mathbf{2 b}, \mathbf{2 a d})$ or more complex substrate-mimetic side chains $(\mathbf{1 v}, \mathbf{1 w})$; these were installed without activation of the radical precursor halide.

\section{On-protein heterolytic reactivity}

Halides $(\mathbf{1} \mathbf{s}, \mathbf{1 t}, \mathbf{1} \mathbf{u}, \mathbf{2 b}, \mathbf{2 a d}, \mathbf{1 v}, \mathbf{1 w})$ are potentially powerful general $2 e^{-}$electrophilic side chains and afford a novel, on-protein heterolytic reaction platform for potential conjugation with off-protein nucleophiles. By varying the $\mathrm{pH}$, the nucleophile concentration and the halide, it was possible to selectively facilitate intermolecular nucleophilic substitution at $\mathrm{C}-$ Hal (Fig. 2b), thereby creating C-S, C-P and C-N bonds (creating, for example, methyllysine PTMs and $\mathrm{N}_{3}$-giving Anl) and even direct, Finkelstein-type halogen exchange $(\mathrm{Br} \rightarrow \mathrm{Cl}$ or $\mathrm{I} \rightarrow \mathrm{Cl}$ ), allowing further tuning of electrophile reactivity. Therefore, this is a direct strategic inversion of common practice in the field of protein conjugation (using prevalen nucleophiles in proteins such as Cys and Lys to target off-protein electrophiles).

\section{On-protein homolytic reactivity}

Mono- and difluoro-pySOOF side chains (2ae, 2af) suggested immediate potential for generating on-protein side-chain radicals (Fig. 2a). In agreement with the reactivity of offprotein pySOOF, on-protein initiation of mono-fluoro-pySOOF side chain $\mathbf{2 a e}$ failed. However, when histone-H3-pySOOF9 (containing di-fluoro-pySOOF side chain 2af at site 9) was activated in the absence of a co-reactant, a reduced product (H3-DfeGly9) was cleanly generated (Fig. 2a and Supplementary Tables 23, 24), consistent with on-protein carbon radical initiation and $\mathrm{C} \gamma-\mathrm{H}$ bond formation.

To test the scope of this on-protein carbon radical, we targeted the more challenging $\mathrm{C} \gamma-\mathrm{X}$ bonds. First, $\mathrm{C} \gamma-\mathrm{C} \delta$ bonds were formed using various off-protein, $\mathrm{C}=\mathrm{C}$ radical acceptors (Fig. 2a, bottom right and Supplementary Tables 25-34): mono-/di-substituted polarized acceptors, as well as challenging, tri-substituted and less-polarized acceptors, albeit with lower conversion efficiencies. Indeed, such was the $\mathrm{C} \gamma-\mathrm{C} \delta$ bond-formation efficiency that it allowed on-protein $\mathrm{C}-\mathrm{C}$ bond-forming side-chain oligomerization/polymerization $(\mathrm{C} \gamma-$ $\mathrm{C} \delta-\mathrm{C} \varepsilon-\ldots$ ). This could be observed directly by intact protein mass spectrometry (MS) (for example, single/double/triple/quadruple side-chain addition unit growth for $\mathrm{N}$ acetyldehydroalanine; Fig. 2a, inset at bottom right). Furthermore, oligomerization could be modulated by the monomer, $\mathrm{Fe}$ (II) and/or photocatalyst loadings (for example, a change from 25 to 125 equiv. $N$-acetyldehydroalanine and from 2 to 4 equiv. Cat1 shifted the oligomer mono-:di-:tri-:tetra- ratio from 15:65:25:0 to 0:37:45:18) as well as by higher monomer reactivity (for example, acrylamide gave up to a side-chain hexamer; see Supplementary Table 34). This demonstrated site-selective, side-chain $\mathrm{C}-\mathrm{C}$ synthesis of up to 14 carbons in length in a protein.

Second, we explored $\mathrm{C} \gamma$-heteroatom bonds: stable nitroxide allowed $\mathrm{C} \gamma-\mathrm{O} \delta$ bond formation ( $>90 \%$; Fig. 2a middle left and Supplementary Table 35), and Se-Se bond cleavage even allowed installation of difluorophenyl-SeMet (>90\%; Fig. 2a bottom centre and Supplementary Table 36) through $\mathrm{C} \gamma-\mathrm{Se} \delta$ bond formation.

Finally, we explored the potential of such on-protein radical chemistry in covalent, protein-protein hetero-dimer formation, a challenging and rare application that, to our knowledge, has not been previously achieved by controlled C(sp3)-C(sp3) bond formation. When H3-pySOOF9 $(\sim 15 \mathrm{kDa})$ was initiated under photocatalytic conditions in the presence of the equimolar, Dha-containing protein histone-eH3.1-Dha9 ( $\sim 18 \mathrm{kDa})$, a crosslinked protein $(\sim 33 \mathrm{kDa}$ ) adduct was immediately observed (Fig. 2a bottom left and Supplementary Table 37), consistent with heteromeric crosslinking.

\section{Probing of post-translational enzymes}

Suitable side chains allow potential post-translationally modified (PTM) mimicry (Fig. 3) which was tested through installation of acetyl- (AcLys/KAc,1m) and benzoyl-lysine (BzLys/KBz,1n) side chains (using BACED) as well as $\mathrm{H} \rightarrow \mathrm{F}$-labelled lysine analogues $\left(\mathrm{K}\left[\gamma \mathrm{F}_{2}\right] \mathrm{Ac}\right.$, 2k and $\mathrm{K}\left[\gamma \mathrm{F}_{2}\right]$, 2f, using pySOOF). First, human histone eH3.1 proteins eH3.1KAc18 and eH3.1-KBz18 enabled time-course studies of NAD+-dependent deacylase Sirt2, which not only confirmed the suggested ${ }^{39}$ Sirt2 activity on full-length proteins, but also revealed a strong, previously undetermined substrate $\mathrm{KAc}>\mathrm{KBz}$ selectivity by Sirt2 in a full-length protein $\left(k_{\text {cat }} / K_{\mathrm{M}, \text { app }}(\mathrm{eH} 3.1-\mathrm{K} 18 \mathrm{Ac}): k_{\mathrm{cat}} / K_{\mathrm{M}, \text { app }}(\mathrm{eH} 3.1-\mathrm{K} 18 \mathrm{Bz})>100: 1\right)$ (Fig. 3a) 
In addition to these constitutionally native side chains, we also tested $\mathrm{H} \rightarrow$ F-labelled $\mathrm{K}\left[\gamma \mathrm{F}_{2}\right] \mathrm{Ac} 2 \mathbf{2}$ and $\mathrm{K}\left[\gamma \mathrm{F}_{2}\right] \mathbf{2 f}$ side chains. The centrally placed $\gamma$-carbon- $\mathrm{F}_{2}$ label allowed in situ reporting of the modification state of these side chains, in three ways (Extended Data Figs. 9 , 10): chemical/modification state (for example, $\pm \mathrm{Ac}$ ), stereochemical state (for example, $\mathrm{D}$ versus-L processing) and assembly state (protein mono-/multimer). The identity of eH3.1$\mathrm{K} 18$ versus eH3.1-K18Ac was sensitively distinguished by the ${ }^{19} \mathrm{~F}$ nuclear magnetic resonance (NMR) shift, despite the five-bond distance from the $\gamma$-carbon- $\mathrm{F}_{2}$ label to the site of change ( $\mathbf{2} \mathbf{f} \rightarrow \mathbf{2 k} ; \delta_{\mathrm{F}}=-98.0 \rightarrow-99.4 ;$ Fig. $3 \mathrm{~b}$ ), as were other side-chain variations, such as H3.1-K9 $\rightarrow \mathrm{KAc} 9 \rightarrow \mathrm{K}_{\mathrm{me} 3}$ 9, $\mathbf{2} \mathbf{f} \rightarrow \mathbf{2 k} \rightarrow \mathbf{2} \mathbf{j}$, H3.1-M9 (2x), H3.1-E9 (2u) (Extended Data Fig. 9). The diverse scope of further side chains (Extended Data Fig. 8) would also allow such monitoring for heteroatom variation ( $\mathrm{N} \rightarrow \mathrm{O}$-'deaza-oxo'-H3.1- $\mathrm{K}_{o} \mathrm{Ac}(\mathbf{2 r})$ ) or precisely assaying the side-chain methionine (Met) oxidation state (H3.1-M27 $\rightarrow \mathrm{M}_{\mathrm{ox}} 27 \rightarrow \mathrm{M}_{\mathrm{ox} 22} 27$ $2 x \rightarrow 2 y \rightarrow 2 z)$.

Moreover, through additional correlated simulation of ${ }^{19} \mathrm{~F}$ NMR multiplicity (Fig. 3b), the $\gamma-\mathrm{F}_{2}$ label allowed simultaneous in situ on-protein reporting on both the modification state (KAc $\rightarrow \mathrm{K}$ at the $\mathrm{N} \varepsilon$ site, five bonds 'down' the side chain) and, by virtue of the highly sensitive $\mathrm{CF}_{2}$ diastereotopicity, the stereochemical state (and hence processing selectivity of $\mathrm{L}$ versus $\mathrm{D}$ at the $\mathrm{C} \alpha$ site, three bonds 'up' the side chain). This $\alpha-\gamma-\mathrm{N} \varepsilon$ sensitivity along the full length of the side chain revealed that HDAC-Sirt2 deacylation displays an $\alpha$-L $>\alpha$-D selectivity preference at eH3.1-KAc18 of $>14\left(\Delta \Delta \mathrm{G}^{\sigma}>6.6 \mathrm{~kJ} \mathrm{~mol}^{-1}\right.$; Extended Data Fig. 10), despite the six 6-bond distance to $\mathrm{N} \varepsilon$. To our knowledge, such simultaneous, real-time determinations of substrate- and stereoselectivity in intact proteins have not been previously possible.

Finally, the sensitivity of the $\gamma-F_{2}$ label could be applied to monitor differential folding and assembly states in a single protein: full step-wise assembly ${ }^{40}$ of H3-DfeGly9 histone into an octamer (unfolded-H3 monomer $\rightarrow$ folded-H3 monomer $\rightarrow(\mathrm{H} 3)_{2} \cdot(\mathrm{H} 4)_{2}$ hetero-tetramer $\rightarrow(\mathrm{H} 3)_{2} \bullet(\mathrm{H} 4)_{2} \bullet(\mathrm{H} 2 \mathrm{~A})_{2} \bullet(\mathrm{H} 2 \mathrm{~B})_{2}$ hetero-octamer) was achieved even at microgram scales (Extended Data Fig. 10)

\section{Alkylator-mimicking proteins trap buried protein-protein interfaces}

The electrophilic halide side chains included those with side-chain lengths that were well matched to Lys (bromonorleucine (Bnl, 1t), bromohomonorleucine (Bhn, 1u), iodonorleucine (Inl, 1s); Extended Data Fig. 8), which enabled the design of 'protein alkylators' with potential context-dependent reactivity. If designed correctly, these would remain inactive under typical conditions in a biological mixture, but would then display enhanced alkylative reactivity in a 'guided' manner by virtue of solvent exclusion, effective molarity ${ }^{41,42}$ and proper mimicry when suitably engaged at a protein-protein interface (PPI). Such a system would require a critical balance in electrophilic reactivity and native shape fidelity (Extended Data Fig. 11a), which has been presciently highlighted as a key goal in protein science (see Supplementary Discussion 5$)^{18}$

Site-selective insertion of the minimally sized alkylhalide side chains Bnl (1t), Bhn (1u) and Inl (1s) into proteins has not been previously possible. By mimicking the binding of Lys side chains more closely, it was possible to probe even buried PPIs without artefacts. We tested potential buried ${ }^{43}$ and transient (substrate•enzyme) PPIs using Bhn (1u) at three sites $(4,9,27)$ that are normally occupied by Lys in C-terminally FLAG-HA-tagged histone eH3.1. When incubated with a partner enzyme that processes (and so binds) Lys, Lysdemethylase-KDM4A was observed to crosslink exclusively to Bhn-containing eH3.1-Bhn4 eH3.1-Bhn9 and eH3.1-Bhn27, but not to WT histone eH3.1 (Fig. 3c). The Lys- 'guided' nature of this crosslinking was consistent with zero crosslinking from incubations with other proteins: neither Cys-rich serum albumin nor the known nucleosomal binding partner histone H4-H3•H4 PPI involves Lys ${ }^{4,9,27,44}$, whereas the H3•KDM4A PPI does ${ }^{43}$. This seeming PPIselective reaction was further confirmed by MS/MS analysis (Fig. 3c, Extended Data Fig. $11 \mathrm{c}$ ) of crosslinking to KDM4A-Cys234,Cys $306^{43}$ located in the buried Zn-binding domain in H3•KDM4A PPI, as well as by real-time fluorescent monitoring of $\mathrm{Zn}$ ejection (Fig. 3c, Extended Data Fig. 11b ${ }^{45}$ by eH3.1-Bhn9 but not by WT-eH3.1. Moreover, when incubated with human-cell (HeLa) nuclear lysate, eH3.1-Bhn9 showed the ability of enhancing capture of interaction partners via eH3.1-adduct formation (Extended Data Fig. 11e)

The unusual reactivity of these alkylator proteins was further illustrated by the observation of an inter-protein Williamson-type (-C-O-C-) ether formation that, to our knowledge, is unprecedented ${ }^{16}$ (Extended Data Fig. 11c, d) and has a typical rate that is seemingly too low $\left(k_{\text {app }}<10^{-4} \mathrm{M} \mathrm{s}^{-1}\right)^{46,47}$ to allow effective crosslinking (see Supplementary Discussion 6). This observation of inter-protein (Extended Data Fig. 11c, d) H3-tail•H3-tail $\mathrm{C}-\beta-\mathrm{O}-\mathrm{CH}_{2}-\mathrm{Bhn} 4$ trapping may suggest transient interactions; a JmjN domain found next to a catalytic JmjC domain in KDM4A has recently been implicated as a functionally essential dimerization motif in cellular models ${ }^{48}$. Together with reported observations of KDM4A homo-multimers in vitro ${ }^{49}$, this could suggest a model (Extended Data Fig. 11d) in which 
KDM4A multimers sample pre-existing $\mathrm{H} 3 \cdot \mathrm{H} 3$ dimers, and indicates further potential of precisely mimicking residues such as Bhn to create new speculative mechanistic models.

\section{Discussion}

Our strategy for photoredox-initiation of carbon radical precursors displays chemoselectivity that is precise enough for broad installation of previously difficult, even reactive, side chains. Limitations to our process remain: the $\mathrm{H}_{3} \mathrm{C}^{*}$ and argon radical precursors failed, perhaps owing to higher redox barriers to initiation or to rapid termination that outstrips addition; however, the pySOOF system does allow use of $\mathrm{HF}_{2} \mathrm{C}$. Notably, we also observed examples of the site-selective creation of quaternary sites in proteins through dual carbon radical addition (for example, dual Bn` to give 4-benzyl,3-phenyl-Aib, BFab at $\sim 80 \%$; Extended Data Fig. 3a). Although not the focus of this work, the ability to vary the conditions for the formation of such centres using longer-lived carbon radicals with more potent photocatalysts (here Cat3 $>$ Cat1) to quench/terminate an on-protein $\alpha$-carbon radical is an exciting additional observation, which suggests future design of Gem,Gem- $\alpha, \alpha$-bisalkylated motifs known ${ }^{50}$ to control stability and conformation.

Our discovery of new crosslinks using previously inaccessible unnatural amino acids in proteins (for example, Bhn) suggests that precise mimicry of residues in PPIs may drive new chemistries, and hence selectivities. Whereas current crosslinking methods nonspecifically 'fix' (for example, formaldehyde, bis-esters), and hence trap, complexes that are longer-lived or more favoured, our results here suggest that the future application of crosslinks could enable the exploitation of reactivity enhanced by effective molarity (see Supplementary Discussion 6) to precisely cross-react minimal, size-matched side chains (for example, Bhn) even in transient, reactive interactions. Importantly, in this scenario it is the relative rate enhancement caused by the environment that is important, rather than the inherent rate of reactivity. We speculate therefore that better crosslinking selectivities may now be designed around new amino acids with unusual chemistries (for example, Williamson ether formation) and counterintuitively lower (not higher) reactivities that work in rare, but more information-rich and relevant, contexts (for example, insertion into precisely matching PPIs that drive effective molarity). Moreover, this has enabled complex, activity-based protein inhibition through the modification of conserved active-site residues (for example, covalent inhibition of KDM4A by eH3.1-Bhn9). In this way, one may consider future protein analogues - 'protein covalent inhibitors' - that act akin to emerging, targeted small-molecule covalent inhibitors ${ }^{51}$, but with enhanced potency and selectivity that exploits PPIs.
The observed requirement for continual irradiation in our light-driven approach enables on-off temporal control (Extended Data Figs. 3e, 7). This suggests not only chemical precision in individual proteins but also potential future use of defined spatiotemporal irradiation ${ }^{21,52}$ to control states of protein ensembles over time and site (for example, tissues). When also paired with in cellulo generation of $\mathrm{Dh}^{53}$, the chemical side-chain versatility that we have observed could drastically improve our ability to probe complex biological systems with atomic precision using the tissue-penetrating trigger of light. To this future end, we have also shown that various biogenic catecholamines (Extended Data Fig. 3f) function in the BACED manifold. This, along with the endogenous presence of $\mathrm{Fe}(\mathrm{II})$ for pySOOF reactivity, suggests promise for in vivo reactivity.

Online content Any methods, additional references, Nature Research reporting summaries, source data, extended data, supplementary information, acknowledgements, peer review information; details of author contributions and competing interests; and statements of data and code availability are available at [DOI link].

Received 8 November 2019; accepted 15 July 2020

1. Walsh, C. T., Garneau-Tsodikova, S. \& Gatto, G. J., Jr. Protein posttranslational modifications: the chemistry of proteome diversifications. Angew. Chem. Int. Ed. $\mathbf{4 4}$ 7342-7372 (2005)

2. Deribe, Y. L., Pawson, T. \& Dikic, I. Post-translational modifications in signal integration. Nat. Struct. Mol. Biol. 17, 666 (2010).

3. Howard, C. J., Yu, R. R., Gardner, M. L., Shimko, J. C. \& Ottesen, J. J. Chemica and biological tools for the preparation of modified histone proteins. Top. Curr. Chem. 363, 193-226 (2015).

4. Yang, A., Cho, K. \& Park, H.-S. Chemical biology approaches for studying posttranslational modifications. RNA Biol. 15, 427-440 (2018).

5. Ducry, L. \& Stump, B. Antibody-drug conjugates: linking cytotoxic payloads to monoclonal antibodies. Bioconjug. Chem. 21, 5-13 (2010).

6. Hinner, M. J. \& Johnsson, K. How to obtain labeled proteins and what to do with them. Curr. Opin. Biotechnol. 21, 766-776 (2010).

7. Leitner, A. et al. Probing native protein structures by chemical cross-linking, mass spectrometry, and bioinformatics. Mol. Cell. Proteomics 9, 1634 (2010). 
8. Wang, L., Brock, A., Herberich, B. \& Schultz, P. G. Expanding the genetic code of Escherichia coli. Science 292, 498 (2001).

9. Dumas, A., Lercher, L., Spicer, C. D. \& Davis, B. G. Designing logical codon reassignment - expanding the chemistry in biology. Chem. Sci. 6, 50-69 (2015).

10. Chin, J. W. Expanding and reprogramming the genetic code. Nature 550, 53-60 (2017).

11. Klemes, Y., Etlinger, J. D. \& Goldberg, A. L. Properties of abnormal proteins degraded rapidly in reticulocytes. Intracellular aggregation of the globin molecules prior to hydrolysis. J. Biol. Chem. 256, 8436-8444 (1981).

12. Chalker, J. M. \& Davis, B. G. Chemical mutagenesis: selective post-expression interconversion of protein amino acid residues. Curr. Opin. Chem. Biol. 14, 781-789 (2010)

13. Wright, T. H., Vallée, M. R. J. \& Davis, B. G. From chemical mutagenesis to postexpression mutagenesis: a 50 year Odyssey. Angew. Chem. Int. Ed. 55, 5896-5903 (2016)

14. Wright, T. H. et al. Posttranslational mutagenesis: a chemical strategy for exploring protein side-chain diversity. Science 354, aag1465 (2016).

15. Yang, A. et al. A chemical biology route to site-specific authentic protein modifications. Science 354, 623-626 (2016).

16. Tamura, T. \& Hamachi, I. Chemistry for covalent modification of endogenous/native proteins: from test tubes to complex biological systems. J. Am. Chem. Soc. 141, 2782-2799 (2019).

17. Wright, T. H. \& Davis, B. G. Post-translational mutagenesis for installation of natural and unnatural amino acid side chains into recombinant proteins. Nat. Protocols 12, 2243-2250 (2017).

18. Sletten, E. M. \& Bertozzi, C. R. Bioorthogonal chemistry: fishing for selectivity in a sea of functionality. Angew. Chem. Int. Ed. 48, 6974-6998 (2009).

19. Imiołek, M. et al. Selective radical trifluoromethylation of native residues in proteins J. Am. Chem. Soc. 140, 1568-1571 (2018).
20. Isenegger, P. G. \& Davis, B. G. Concepts of catalysis in site-selective protein modifications. J. Am. Chem. Soc. 141, 8005-8013 (2019).

21. Lim, R. K. V. \& Lin, Q. Photoinducible bioorthogonal chemistry: a spatiotemporally controllable tool to visualize and perturb proteins in live cells. Acc. Chem. Res. $\mathbf{4 4}$, 828-839 (2011).

22 Twilton, J. et al. The merger of transition metal and photocatalysis. Nat. Rev. Chem. 1, 0052 (2017)

23. Prier, C. K., Rankic, D. A. \& MacMillan, D. W. C. Visible light photoredox catalysis with transition metal complexes: applications in organic synthesis. Chem. Rev. 113, 5322-5363 (2013).

24. Bloom, S. et al. Decarboxylative alkylation for site-selective bioconjugation of native proteins via oxidation potentials. Nat. Chem. 10, 205 (2018).

25. Yu, Y. et al. Chemoselective peptide modification via photocatalytic tryptophan $\beta$ position conjugation. J. Am. Chem. Soc. 140, 6797-6800 (2018).

26. de Bruijn, A. D. \& Roelfes, G. Chemical modification of dehydrated amino acids in natural antimicrobial peptides by photoredox catalysis. Chemistry 24, 11314-11318 (2018).

27. Povie, G. et al. Catechols as sources of hydrogen atoms in radical deiodination and related reactions. Angew. Chem. Int. Ed. 55, 11221-11225 (2016).

28. Matsui, J. K., Lang, S. B., Heitz, D. R. \& Molander, G. A. Photoredox-mediated routes to radicals: the value of catalytic radical generation in synthetic methods development. ACS Catal. 7, 2563-2575 (2017).

29. Robole, Z. M., Rahn, K. L., Lampkin, B. J., Anand, R. K. \& VanVeller, B. Tuning the electrochemical redox potentials of catechol with boronic acid derivatives. $J$. Org. Chem. 84, 2346-2350 (2019).

30. Ghosh, T. et al. Mixed-ligand complexes of ruthenium(II) containing new photoactive or electroactive ligands: synthesis, spectral characterization and DNA interactions. J. Biol. Inorg. Chem. 10, 496 (2005).

31. Dolbier, W. R. Structure, reactivity, and chemistry of fluoroalkyl radicals. Chem. Rev. 96, 1557-1584 (1996). 
32. Zhang, L., Dolbier, W. R., Sheeller, B. \& Ingold, K. U. Absolute rate constants of alkene addition reactions of a fluorinated radical in water. J. Am. Chem. Soc. 124 6362-6366 (2002).

33. O'Hagan, D. Understanding organofluorine chemistry. An introduction to the C-F bond. Chem. Soc. Rev. 37, 308-319 (2008).

34. Lemos, A., Lemaire, C. \& Luxen, A. Progress in difluoroalkylation of organic substrates by visible light photoredox catalysis. Adv. Synth. Catal. 361, 1500-1537 (2019).

35. Rong, J. et al. Radical fluoroalkylation of isocyanides with fluorinated sulfones by visible-light photoredox catalysis. Angew. Chem. Int. Ed. 55, 2743-2747 (2016)

36. Berlicki, L., Obojska, A., Forlani, G. \& Kafarski, P. Design, synthesis, and activity of analogues of phosphinothricin as inhibitors of glutamine synthetase. J. Med. Chem. 48, 6340-6349 (2005).

37. Griller, D. \& Ingold, K. U. Free-radical clocks. Acc. Chem. Res. 13, 317-323 (1980).

38. Chen, Y., Kamlet, A. S., Steinman, J. B. \& Liu, D. R. A biomolecule-compatible visible-light-induced azide reduction from a DNA-encoded reaction-discovery system. Nat. Chem. 3, 146-153 (2011).

39. Huang, H. et al. Lysine benzoylation is a histone mark regulated by SIRT2. Nat. Coтmun. 9, 3374 (2018).

40. Dyer, P. N. et al. Reconstitution of nucleosome core particles from recombinant histones and DNA. Methods Enzymol. 375, 23-44 (2003).

41. Page, M. I. \& Jencks, W. P. Entropic contributions to rate accelerations in enzymic and intramolecular reactions and the chelate effect. Proc. Natl Acad. Sci. USA 68 1678-1683 (1971)

42. Krishnamurthy, V. M., Semetey, V., Bracher, P. J., Shen, N. \& Whitesides, G. M Dependence of effective molarity on linker length for an intramolecular protein-ligand system. J. Am. Chem. Soc. 129, 1312-1320 (2007).

43. $\mathrm{Ng}, \mathrm{S}$. S. et al. Crystal structures of histone demethylase JMJD2A reveal basis for substrate specificity. Nature 448, 87-91 (2007)
44. English, C. M., Adkins, M. W., Carson, J. J., Churchill, M. E. \& Tyler, J. K. Structural basis for the histone chaperone activity of Asf1. Cell 127, 495-508 (2006).

45. Meeusen, J. W., Tomasiewicz, H., Nowakowski, A. \& Petering, D. H. TSQ (6methoxy-8-p-toluenesulfonamido-quinoline), a common fluorescent sensor for cellular zinc, images zinc proteins. Inorg. Chem. 50, 7563-7573 (2011).

46. Freedman, H. H. \& Dubois, R. A. An improved Williamson ether synthesis using phase transfer catalysis. Tetrahedr. Lett. 16, 3251-3254 (1975).

47. Mandal, S. et al. A review on the advancement of ether synthesis from organic solvent to water. RSC Advances 6, 69605-69614 (2016).

48. Levin, M., Stark, M. \& Assaraf, Y. G. The JmjN domain as a dimerization interface and a targeted inhibitor of KDM4 demethylase activity. Oncotarget $9,16861-16882$ (2018).

49. Shin, S. \& Janknecht, R. Diversity within the JMJD2 histone demethylase family. Biochem. Biophys. Res. Commun. 353, 973-977 (2007).

50. Karle, I. L. \& Balaram, P. Structural characteristics of .alpha.-helical peptide molecules containing Aib residues. Biochemistry 29, 6747-6756 (1990).

51. Lonsdale, R. \& Ward, R. A. Structure-based design of targeted covalent inhibitors. Chem. Soc. Rev. 47, 3816-3830 (2018).

52. Angerani, S. \& Winssinger, N. Visible light photoredox catalysis using ruthenium complexes in chemical biology. Chemistry 25, 6661-6672 (2019).

53. Yang, B. et al. Genetically introducing biochemically reactive amino acids dehydroalanine and dehydrobutyrine in proteins. J. Am. Chem. Soc. 141, 7698-7703 (2019).

Publisher's note: Springer Nature remains neutral with regard to jurisdictional claims in published maps and institutional affiliations. 


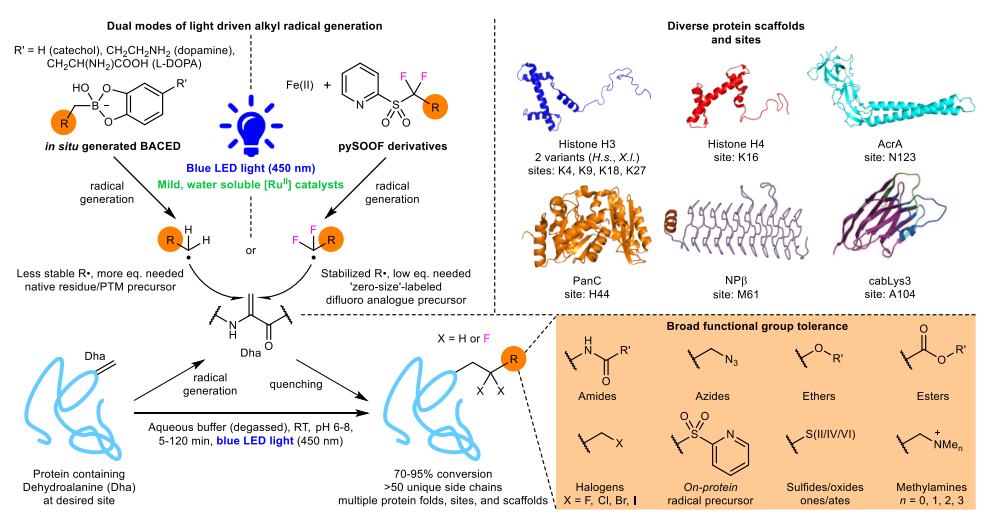

Fig. 1 | Site-selective, light-driven post-translational protein editing. The excitation of mild, water-soluble, protein-compatible $\mathrm{Ru}^{\text {II }}$ photocatalysts with blue light enables dual modes of alkyl radical generation from complementary radical precursors with low oxidative exposure of protein substrates $\left(E_{\mathrm{ox}}<+1.0 \mathrm{~V}\right)$. In situ-generated BACEDs release less stable alkyl radicals that, when used in higher abundance (100-2,000 equiv.), react selectively with the SOMOphile dehydroalanine (Dha) to install constitutively traceless, side-chain residues in natural, unnatural and PTM form. pySOOF derivatives release stabilized $\mathrm{RF}_{2} \mathrm{C}^{\circ}$ radicals, requiring even lower substrate concentrations ( $2-5$ equiv.), that also efficiently react with Dha to install the corresponding side chains containing 'zero-size' difluoro labels (purple) at the $\gamma$ carbon $\left(\mathrm{C} \gamma \mathrm{H}_{2} \rightarrow \mathrm{C}_{\mathrm{F}}\right)$. These low- $E_{\mathrm{ox}}$, mild conditions not only allow application to diverse protein scaffolds, but are also tolerated by reactive side-chain groups, allowing the direct, site-selective insertion of unprecedented chemical functionality (bottom right, $>50$ unique native or difluoro-labelled side chains in proteins; see Extended Data Fig 8), RT, room temperature; LED, light-emitting diode.

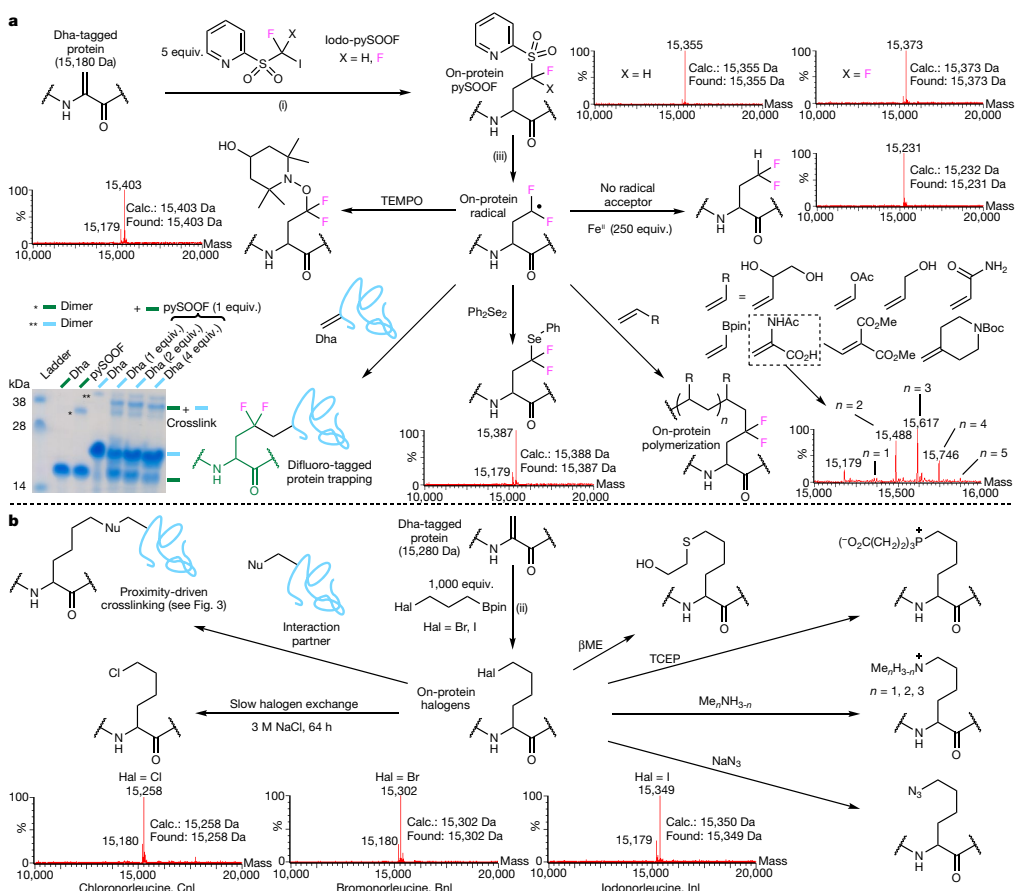

Fig. 2 | On-protein homolytic and heterolytic reactivity via installation of a radical precursor and electrophile side chains. a,Utilization of iodo-pySOOF allowed reductive installation of an on-protein pySOOF side chain, which is itself a protein radical precursor. Both mono- and difluoro-pySOOF side chains were installed. Reagents andconditions: (i) histone-H3-Dha9 $(66 \mu \mathrm{M})$, iodo-pySOOF (5 equiv.), $\mathrm{FeSO}_{4} \cdot 7 \mathrm{H}_{2} \mathrm{O}\left(20\right.$ equiv.), $\mathrm{Ru}(\text { bpy })_{3} \mathrm{Cl}_{2}$ (0.4 equiv.), $\mathrm{NH}_{4} \mathrm{OAc}(500 \mathrm{mM}, \mathrm{pH} 6,3 \mathrm{M} \mathrm{GdnHCl}), 50 \mathrm{~W}$ blue LED, RT, 15 min. Intact protein liquid chromatography (LC)-MS (right, top). (iii) After activation under standard conditions, the resulting on-protein radical allowed further protein functionalization via onprotein homolytic bond-forming modes: polymerized with various radical acceptors via $\mathrm{C}-\mathrm{C}$ bond formation (right, bottom); $\mathrm{C}-\mathrm{C}$ trapped by another Dha-containing protein and $\mathrm{C}-\mathrm{C}$ bond-forming protein-protein crosslinking (left, bottom); quenched with stable oxygen nitroxide radical to form $\mathrm{C}-\mathrm{O}$ bonds (left, middle); used to cleave diselenide $(\mathrm{SePh})_{2}$ to form $\mathrm{C}-\mathrm{Se}$ bonds (centre, bottom); or reduced (C-H bond formation) to DfeGly (right, middle). Typical reagents and conditions: histone-H3-pySOOF9 $(66 \mu \mathrm{M})$, substrate (10-250 equiv.), $\mathrm{FeSO}_{4} \cdot 7 \mathrm{H}_{2} \mathrm{O}$ (0-25 equiv.), $\mathrm{Ru}(\text { bpy) })_{3} \mathrm{Cl}_{2} 1-5$ equiv.), $\mathrm{NH}_{4} \mathrm{OAc}(500 \mathrm{mM}$, pH 6, $3 \mathrm{M}$ GdnHCl), 50 W blue LED, RT, 15 min; see Supplementary Tables 23-37 for details; residual Dha, 15,179 Da. b. Utilization of alkylhalide-functionalized BACED reagent allowed

oxidative installation with the $\mathrm{C}-\mathrm{Hal}$ bond unperturbed. This installs on-protein alkylhalide oxidative intallo protein heterolytic bond-forming modes. These on-protein alkylhalide electrophiles were 
reacted through substitution with various small-molecule $\mathrm{P}, \mathrm{S}, \mathrm{N}$ and Hal nucleophiles at higher concentrations, allowing diverse $\mathrm{C}-\mathrm{P}, \mathrm{C}-\mathrm{S}, \mathrm{C}-\mathrm{N}$ and $\mathrm{C}-\mathrm{Hal}$ bond formation (residual Dha, $15,179 / 80 \mathrm{Da}$ ). The ability to install a range of alkylhalide side chains (for example, chloro-(Cnl), bromo-(Bnl), iodo-(Inl) norleucines; intact protein LC-MS, bottom left) also allowed protein-protein crosslinking with interaction partners (see Fig. 3c). Reagents and conditions: (ii) histone H3-Dha9 (66 $\mu \mathrm{M})$, alkylboronic acid pinacol ester ( 1,000 equiv.), catechol (100 equiv.), $\mathrm{Ru}(\mathrm{bpm})_{3} \mathrm{Cl}_{2}$ (10 equiv.), $\mathrm{NH}_{4} \mathrm{OAc}(500 \mathrm{mM}$, pH 6, $3 \mathrm{M} \mathrm{GdnHCl}$ ), 50 W blue LED, RT, $1-3$ h. Calc., calculated; TCEP, tris(2-carboxyethyl)phosphine; $\beta \mathrm{ME}$, betamercaptoethanol.

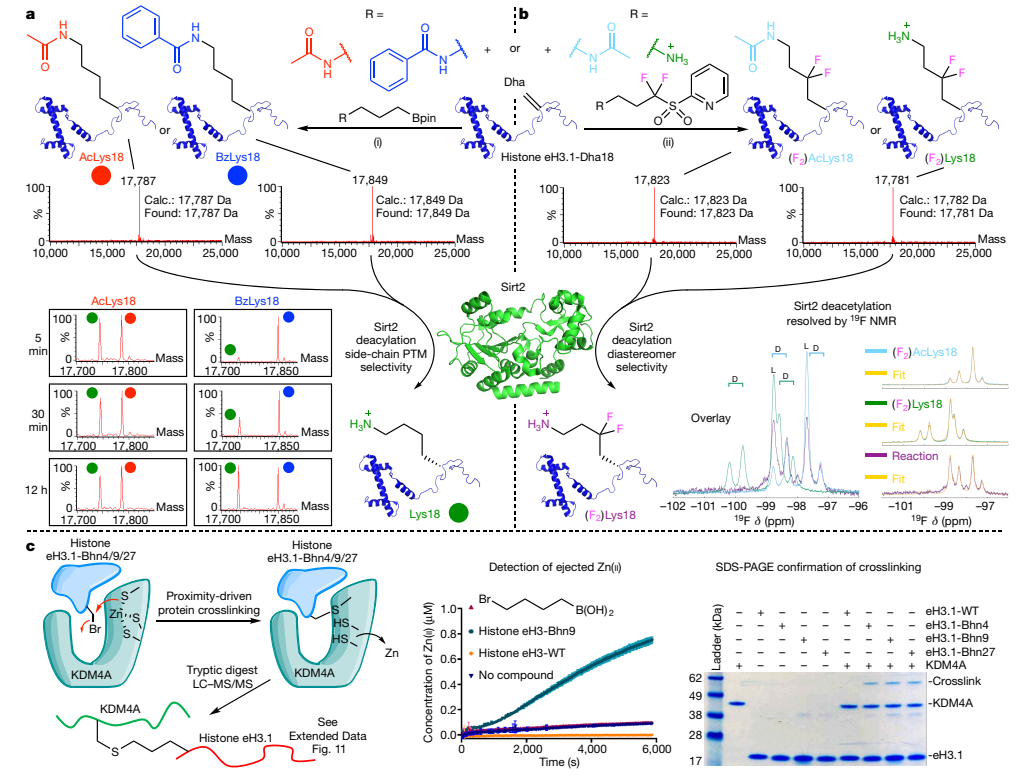

Fig. 3 | Insertion of native, difluoro-labelled and electrophile-containing side chains into proteins provides insight into enzymes that post-translationally modify them. a, The proteins provides insight into enzymes that post-translationally modify them. a, The Sirt2 enzyme displays differnt deacylation rates (via intact protein LC-MS nonitoring) towards installed acetyl (red) and benzoyl (blue) lysine on histone-eH3.1-K18 proteins, thereby confirming both plasticity and selectivity towards acyl groups. Reagents and conditions for installation: (i) histone-H3-Dha9 $(66 \mu \mathrm{M})$, pinacol alkylboronate (250 equiv.) catechol(100 equiv.), $\mathrm{Ru}(\mathrm{bpm})_{3} \mathrm{Cl}_{2}$ (10 equiv.), $\mathrm{NH}_{4} \mathrm{OAc}(500 \mathrm{mM}, \mathrm{pH} 6,3 \mathrm{M} \mathrm{GdnHCl}$ ), $50 \mathrm{~W}$ blue LED, RT, $1 \mathrm{~h}$. b. The activity of Sir2-deacetylation can be directly and sitespecifically monitored via ${ }^{19} \mathrm{~F}$ NMR using a $\mathrm{C}_{\gamma} \mathrm{F}_{2}$-difluoro tag on the $\gamma$ carbon of installed Lys (green) and AcLys (red) side chains. Reagents and conditions: (ii) histone-H3-Dha9 $(66 \mu \mathrm{M})$, alkyl-pySOOF (50 equiv.), $\mathrm{FeSO}_{4} \cdot 7 \mathrm{H}_{2} \mathrm{O}$ (50 equiv.), $\mathrm{Ru}\left(\right.$ bpy) ${ }_{3} \mathrm{Cl}_{2}$ ( 2 equiv.), $\mathrm{NH}_{4} \mathrm{OAc}(500 \mathrm{mM}, \mathrm{pH}$ 6, $3 \mathrm{M} \mathrm{GdnHCl}), 50 \mathrm{~W}$ blue LED, RT, $15 \mathrm{~min}$, $\mathrm{Met}_{\mathrm{ox}}=15,838 \mathrm{Da}$. Although four bonds away from the site of PTM, the $\mathrm{C} \mathrm{F}_{2}$ labels display sufficient sensitivity to the chemical environment $\left(\delta_{\mathrm{F}}\right.$ perturbation) to allow direct simultaneous monitoring of the chemo- and stereoselectivity of Sirt2 during processing (Extended Data Fig. 9). c,

Crosslinking between KDM4A and histone-eH3.1-Bhn4/9/27 traps KDM4A-Zn-binding cysteines near the active site. Coomassie blue SDS-PAGE (centre), tryptic LC-MS/MS (bottom left; see also Extended Data Fig. 3c) and Zn(II) ejection (right) confirm crosslinking between KDM4A and histone-13.1-Bhn9 (see alo Extended Data Fig. 11c). Zn(II)-ejection rates: eH3-Bhn9, $9.27 \pm 0.025 \mathrm{nM} \mathrm{min}^{-1}$; eH3-WT, $0.09 \pm 0.006 \mathrm{nM} \mathrm{min}^{-1}$; $\mathbf{1 u}$ precursor, $0.805 \pm 0.010 \mathrm{nM} \mathrm{min}^{-1}$; no compound, $0.87 \pm 0.028 \mathrm{nM} \mathrm{min}^{-1} ; N=3$ independent experiments. Data plotted are averages \pm s.d. ( $N=3$ technical replicates), $P<0.0001$, oneway ANOVA. See also Extended Data Fig. 11 for further alkylator protein experiments. 


\section{METHODS}

\section{General experiment protocol for BACED and pySOOF reagents}

For all protein-modification reactions, all aqueous buffers, solvents and protein stocks were degassed for at least $8 \mathrm{~h}$ in a glovebox $\left(<6 \mathrm{ppm} \mathrm{O}_{2}\right)$. Then, inside the glovebox a glass vial was charged with the Dha-tagged protein of choice and diluted to the protein concentration of choice with the desired reaction buffer, followed by the sequential addition of an aliquot of catalyst, additive and radical precursor from stocks prepared fresh in buffer (in some cases, small amounts of cosolvent were needed in stock preparation and are explicitly stated when relevant). Afterwards, the reaction mixtures were mixed either by shaking thoroughly or by pipette, capped and transferred out of the glovebox for irradiation with blue LED light $(50 \mathrm{~W})$ for the stated reaction time. After the reaction, an aliquot of the crude mixture was diluted 25 times for MS analysis ( $2 \mu \mathrm{l}$ in $48 \mu \mathrm{l}$ water and $0.1 \%$ formic acid), and conversion efficiencies were calculated relative to the total ion counts. For selected examples (see Supplementary Methods), high ( $>85 \%)$ protein recovery was observed after purification using PD SpinTrap G-25 (GE Healthcare) desalting columns and tracking overall protein absorbance. We note that most of the reaction optimization and $\mathrm{BACED} / \mathrm{pySOOF}$ reagent screening reactions were performed on the model protein substrate X.1. histone H3-Dha9 in denaturing buffe $\left(500 \mathrm{mM} \mathrm{NH} \mathrm{H}_{4} \mathrm{OAc}, 3 \mathrm{M} \mathrm{Gdn} \cdot \mathrm{HCl}\right.$, $\left.\mathrm{pH} 6.0\right)$ at a final concentration of $1 \mathrm{mg} \mathrm{ml}^{-1}(66 \mu \mathrm{M})$ in volumes of 50-200 $\mu$ l. Short reaction times ( $<20 \mathrm{~min})$ did not result in substantial temperature increases, but for longer reaction times ( $>20 \mathrm{~min}$ ) the temperature could be controlled by submerging the reaction vials in a glass beaker filled with water at the desired temperature.

\section{Data availability}

Key raw MS data and primary numerical data for graphical plots have been deposited in the open-access depository ORA-data (https://ora.ox.ac.uk/objects/uuid:2a618e7e-551b-4360a2de-237453d49a31) and all raw data are available from the corresponding authors upon request. MS/MS raw data files have been uploaded to the PRIDE repository (accession number PXD019565). The following additional databases were used: MaxQuant contaminants database (https://www.maxquant.org) and Uniprot Human Database (https://www.uniprot.org/proteomes/UP000005640).

Acknowledgements This research has received funding from the EPSRC (EP/V011359/1), UK Catalysis Hub (EPSRC Portfolio Grant EP/K014668/1; B.G.D., C.F.), the Swiss National Science Foundation (P2BSP2_178609; P.G.I.), BBSRC (BB/P026311/1; B.G.D., V.G., P.G.I.), Oxford-GSK-Crick Chemical
Biology Centre for Doctoral Training Programme (EPSRC, GSK to G.R.) via the EPSRC Systems Approaches to Biomedical Science DTC (EP/R512333/1), Oxford Clarendon Scholarship (to B.J.), Rutherford Foundation (to T.H.W.), UCB (to B.J.B.), Brunei Government Scholarship (to A.W.J.P.) and EU H2020 under Grant Agreement 721902 (to O.A.). We thank S. Hester for experimental support in mass spectrometry, T. Mollner and M. Imiołek for providing small-molecule substrates, S. Faulkner for providing protein, the Chemistry Department workshop for construction of the photoreactor and C. am Ende, W. Stockdale and M. Moomersteeg for discussions.

Author contributions C.F., B.J., P.G.I., T.H.W., V.G. and B.G.D. conceived and designed the experiments. T.H.W. designed and performed initial experiments exploring the oxidative initiation pathway. C.F. performed initial experiments exploring reductive pathways. C.F. optimized the initial photochemical boronate reaction. C.F. designed the high-flux visible-light photoreactor. P.G.I. designed and performed all experiments for the use of pySOOF reagents. C.F., B.J., B.J.B., O.A., P.G.I., A.M.G. and A.W.J.P. synthesized and characterized BACED substrates and catalysts; B.J., P.G.I. and B.J.B. expressed and generated protein starting materials. B.J., C.F., P.G.I., A.M.G. and A.W.J.P. explored the scope of BACED substrate side chains and proteins; B.J. optimized additions of BACED reagents to proteins and explored additional protein scope. P.G.I. designed and performed all experiments exploring the pySOOF reagents with iron/Ru(bpy) 3 and so optimized the corresponding photochemical reaction. P.G.I. designed, synthesized and characterized pySOOF reagents and explored the scope of substrate side chains and proteins. A.W.J.P. and A.M.G. synthesized additional pySOOF and tested them on proteins. J.B.I.S. synthesized additional pySOOF reagents. B.J. developed the on-protein substitution of side-chain alkyl halides with small molecules. B.J. compared the reductive and oxidative initiation of model substrates, explored side reactions and effects of catalysts, as well as methods for recycling side-chain substrate materials from protein reactions. B.J. and A.M.G. conducted ultraviolet-visible highperformance LC analysis of reaction products. L.C. and C.B.-M. made the electrochemical measurements on the basis of which they suggested a mechanistic interpretation along with R.G.C.; P.G.I. designed and conducted all of the on-protein radical reactions and applications. B.J. developed and conducted the on-protein MS enzymatic deacylation assays. B.J. and P.G.I. designed and conducted Sirt2 deacetylation ${ }^{19} \mathrm{~F}$ NMR (and other) enzymetracking reactions; B.J., P.G.I., A.J.B. and B.G.D. analysed the corresponding data. B.J. and P.G.I. conducted and characterized ${ }^{19} \mathrm{~F}$ NMR tracking of histone octamer reconstitution. G.R. and B.J. developed and conducted the zinc-ejection assays. B.J. and C.F. designed and performed protein crosslinking experiments; S.N. and S.M. performed LC-MS/MS experiments and crosslinked product analyses. B.J. developed and conducted lysate crosslinking immunoprecipitation experiments and analysis, and S.N. provided HeLa nuclear extracts. C.F., B.J., S.M., S.N., P.G.I., T.H.W., B.J.B., A.W.J.P., L.C., C.B.-M., G.R., A.K., A.J.B. and B.G.D. collected and/or analysed data. C.F., B.J., P.G.I. and B.G.D. wrote the paper. All authors read and commented on the

Competing interests A patent is being filed that might afford authors royalties were it to be licensed. Additional information

Supplementary information is available for this paper at [DOI link].

Correspondence and requests for materials should be addressed to V.G. or B.G.D. 

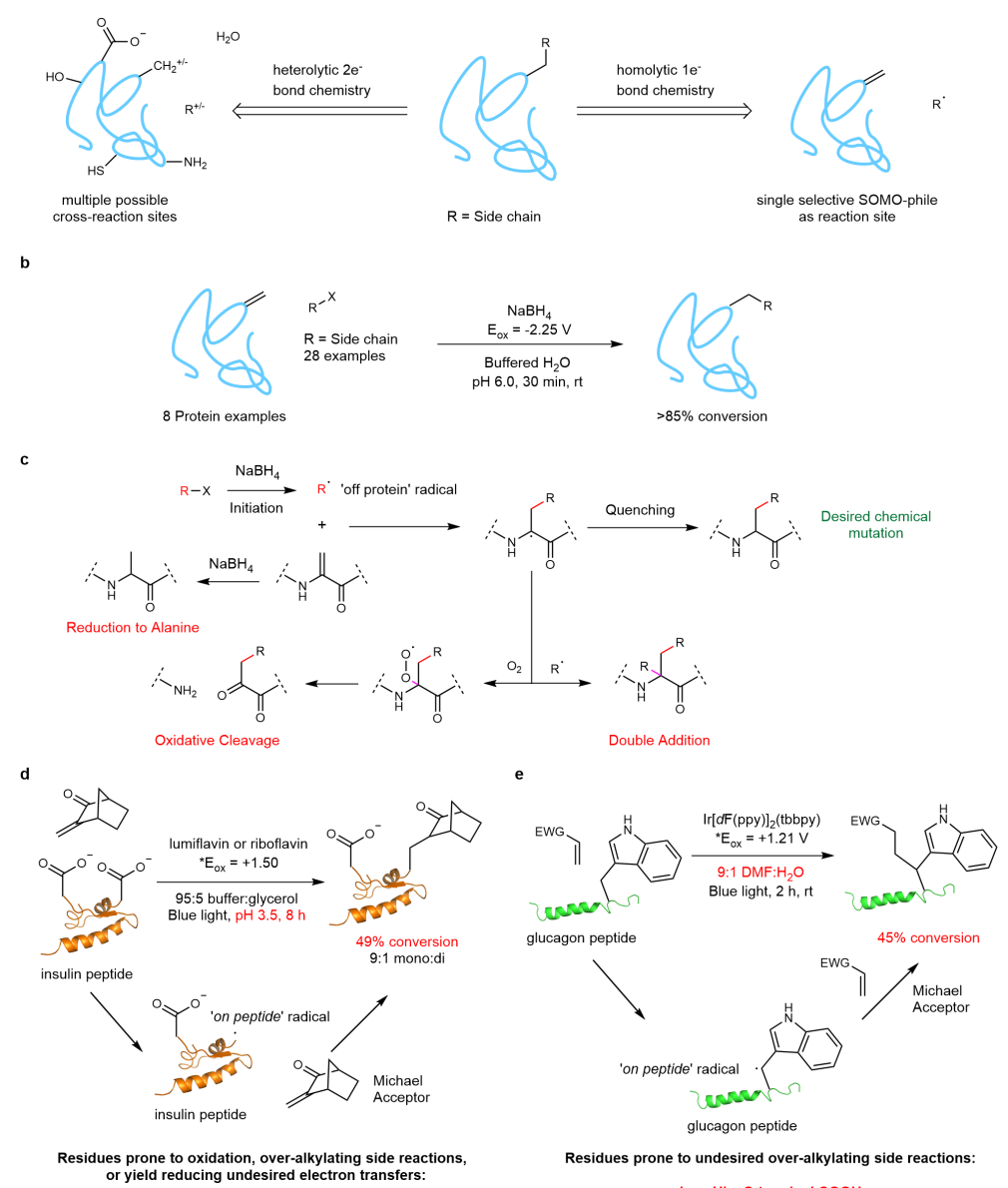

undesired electron transfers:

Lys, His, C-terminal CooH

Extended Data Fig. 1 | Overview of radical side-chain installation and relevant previous literature. a, Retrosynthetic analysis highlights the chemoselective advantages of using carbon radical reagents paired with the radical acceptor Dha (right) over the typical

heterolytic $2 e^{-}$reagents (left) for the site-specific modification of proteins. b, c, Our previous work on radical addition to $\operatorname{Dha}^{14,17}(\mathbf{b})$ and the mechanism highlighting unwanted side reactions (red) (c). d, e, Summaries of previous works ${ }^{24,25}$ using photocatalysts for 'onreactions $($ red $)(\mathbf{c}) . \mathbf{d}, \mathbf{e}$, Summaries of previous works ${ }^{24,25}$ using photocatalysts for
peptide' radical generation for site-selective peptide modification, highlighting their peptide' radical generation for site-selective peptide modifica
limitations and potential for undesired side reactions (red).

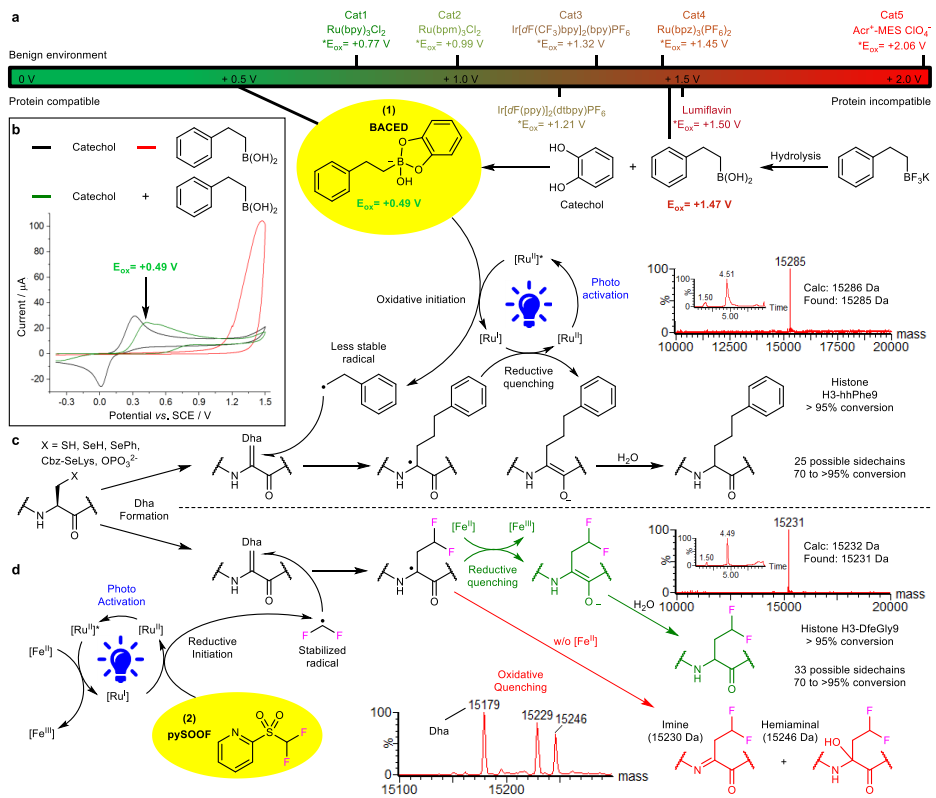

Extended Data Fig. 2 | Complementary strategies for mild protein-compatible photoredox reactions. a, Oxidative-half potential $\left(E_{\mathrm{ox}}\right)$ spectrum showing catalyst compatibility with protein-based chemistry for relevant catalysts found in the literature (bottom and top) and tested in this work (top). b, c, In situ formation of BACED reagents (for side chains 1 , yellow highlight) advantageously allows $\mathrm{Ru}^{\mathrm{II}}$-catalysed, low- $E_{\text {ox }}$ activation (compared to other derivatives) to $\mathrm{RCH}_{2} \cdot$ radicals, which then react with $\mathrm{Dha}$ in proteins to install side chains. Independent and mixed voltammetric responses of $1 \mathrm{mM}$ catechol and $12 \mathrm{mM}$ phenethylboronic acid on GC in PBS, pH 7.10 (inset). See also Extended Data Fig. 4 and Supplementary Discussion 2, 3 for more detailed electrochemical experiments. Intact protein LC-MS (bottom right; chromatogram and mass-to-charge ratio, $m / z$ ) shows homohomophenylalanine (1h) installation into histone $\mathrm{H} 3$ protein. d $\mathrm{Ru}^{\mathrm{II}}$-catalysed activation of pySOOF reagents to $\mathrm{RCF}_{2}{ }^{\circ}$ radicals, which then react with Dha in proteins to install 'zero-size'-labelled side chains. The added $\mathrm{Fe}^{\text {II }}$ drives an unprecedented efficiency (25 equiv. of precursor) by suppressing oxidation by $\mathrm{Ru}^{\mathrm{I} *}$ to imine (and hydrate), suggesting a key role as a reductant (readily available in biology) that quenches the $\alpha$-carbon radical adduct generated during the reaction. Intact protein LC-MS shows that difluoroethylglycine (DfeGly, 2a) installation into histone $\mathrm{H} 3$ protein is successful with $\mathrm{Fe}^{\mathrm{II}}$ (full conversion; top right, chromatogram and $m / z$ ) but not without iron (poor conversion to unwanted side products; bottom centre); see also Extended Data Figs. 5-7 for further details. For the full reaction scope of all side chains (types $\mathbf{1}$ and $\mathbf{2}$ ) edited into proteins, including those allowing previously inaccessible on-protein reactivity, see Extended Data Fig. 8 and Figs. 2, 3. 

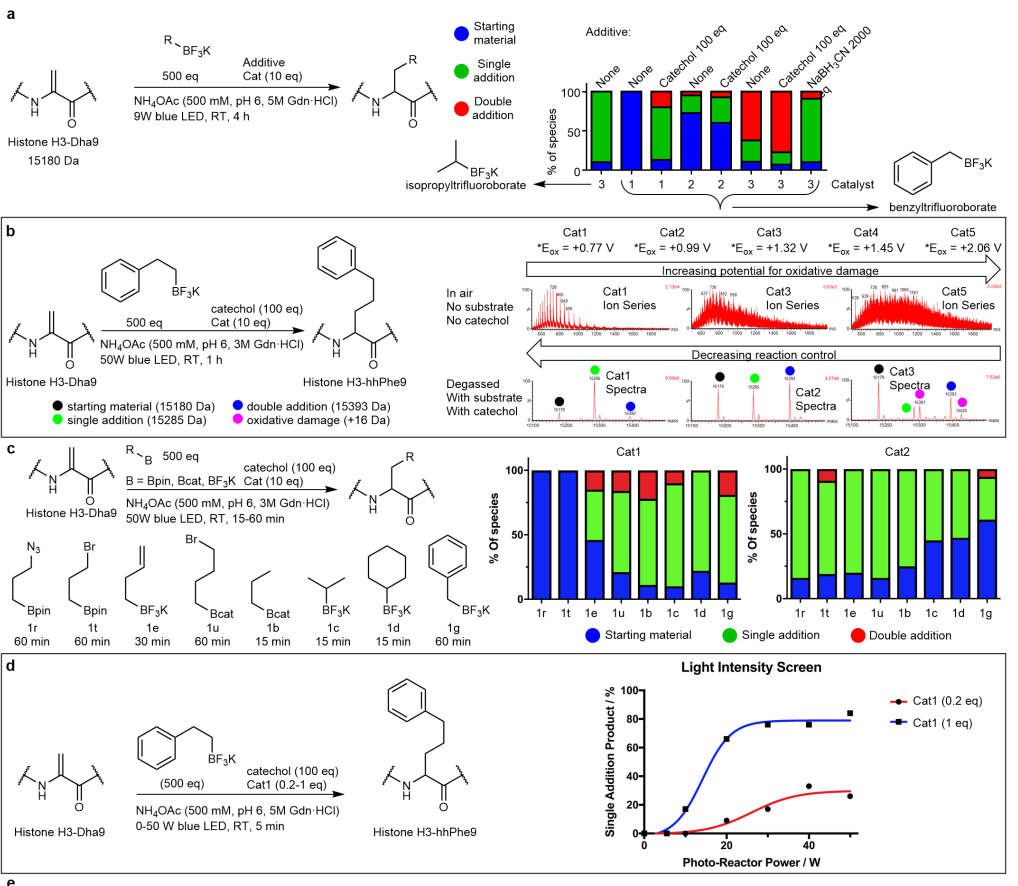

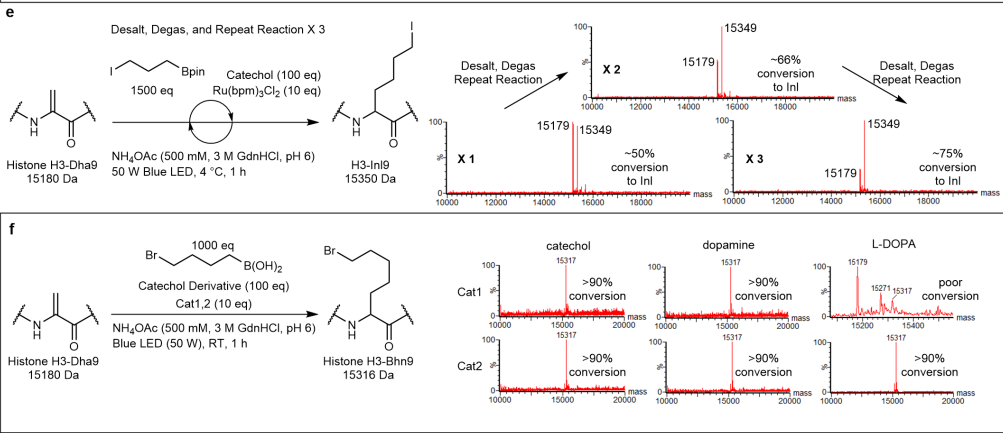

Extended Data Fig. 3 | Investigation and optimization of BACED chemistry. a, A $100 \%$ stacked bar chart $(n=1$, with single data values represented by the $y$-axis span of the corresponding bars) showing the results of initial studies of the oxidation of

benzyltrifluoroborate with different catalyst strengths and additives to achieve selective single addition. Catechol increased the reactivity for all catalysts, leading to the emergence of reactivity with the weakest Cat1 and almost complete conversion to the double-addition product with Cat3, whereas $\mathrm{NaCNBH}_{3}$ with Cat3 successfully quenched the $\alpha$-carbon radical promoting single addition. $\mathbf{b}$, Trends of increasing oxidative damage and decreasing reactio control with higher- ${ }^{*} E_{\mathrm{ox}}$ catalysts with representative LC-MS ion series and spectra (see Supplementary Methods for details). c, A $100 \%$ stacked bar chart ( $n=1$, with single data values represented by the $y$-axis span of the corresponding bars) comparing Cat1 and Cat2 reaction conversions to the single-addition product and unwanted $\alpha$-carbon radical quenching (via either double addition or catechol quenching) for different boronate substrates, arranged with higher- $E_{\text {ox }}$ primary boronate substrates on the left and increasingly stabilized radical precursors on the right. The trends clearly show the utility or necessity of using the stronger Cat2 $\left({ }^{*} E_{\mathrm{ox}}=+0.99 \mathrm{~V}\right)$ for the primary boronate substrates and the increased efficiency when using the weaker Cat1 $(* E=+0.77 \mathrm{~V})$ for the more stabilized radical precursors (secondary and benzyl substrates), probably owing to a slow, controlled release of stable radicals, ensuring efficient addition to Dha instead of self-quenching or overalkylation d, A lightintensity screen shows that incresing light intensity ( $450 \mathrm{~nm}$ blue LED, $0-50 \mathrm{~W}$ ) allows high ing high

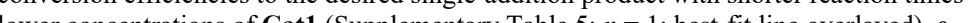
lower con Reaction schene and LC-MS specta for the installation of idonough Inl installation had poor initial conversion ( $\sim 50 \%)$, the only other species present after the reaction was the starting naterial (Dha), allowing successive reactions to push conversion efficiencies to a more reasonable $\sim 75 \%$. f, A screen of catechol derivatives finds that the naturally occurring catecholamines dopamine and L-DOPA could efficiently substitute for the role of catechol. 


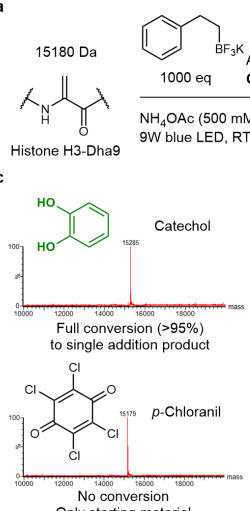

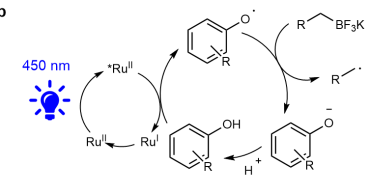
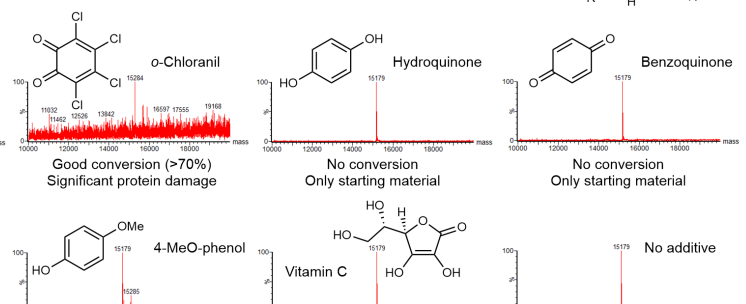

Vita

Only starting material

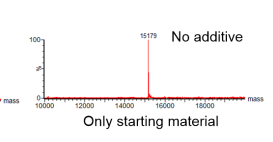

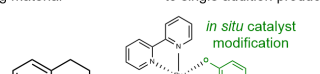
to single addition produ
tin
in situ catalyst
modification

$$
500 \text { eq }
$$$$
\text { Onlystaty }
$$

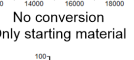

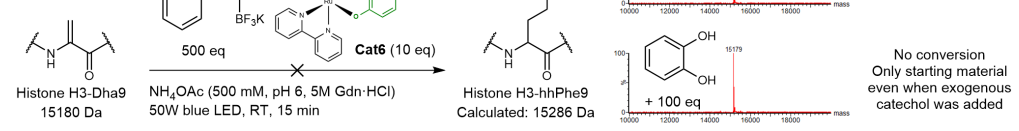

${ }_{\mathrm{Br}} \sim \mathrm{H}_{2} \mathrm{O} \mathrm{OH}_{2}{ }_{\mathrm{f}}$

$15316 \mathrm{D}$

$\overbrace{B r}^{5316 \text { Da }}$

$\mathrm{SO}_{0}^{\circ}+2 \mathrm{H}^{+}+2$

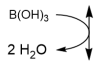

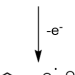

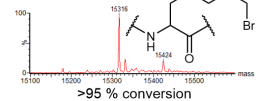
$15 \%$ catechol adduct + (1) 108

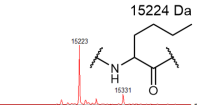
$\mathrm{Cr}^{\circ} \mathrm{O}^{\circ} \mathrm{OH}$

Br- ᄂ

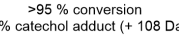

ר证!

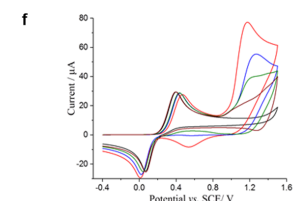

g
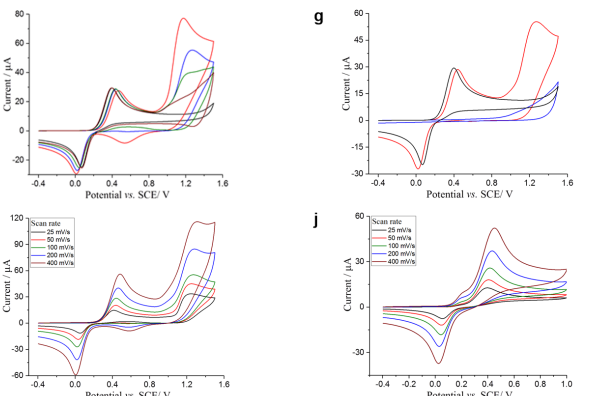

h

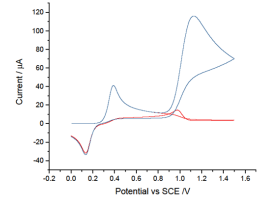

k

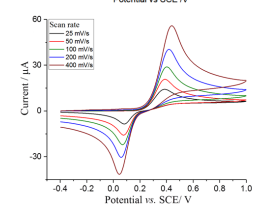

Extended Data Fig. $4 \mid$ Mechanistic investigation of the role of catechol in BACED reactions. a, Reaction scheme screening different quinone derivatives for their influence on the oxidation of potassium phenethyltrifluoroborate and subsequent addition to Dha. $\mathbf{b}$, Potential mechanism of catechol derivatives acting as redox mediators to bridge electron transfer between catalyst and substrate. c, LC-MS results of the quinone derivative screening (shown in $\mathbf{a}$ and $\mathbf{b}$ ) ruled out the mechanism in $\mathbf{b}$ because only 1,2-diols showed substantial activity, with only catechol avoiding protein degradation. d, A potential mechanism of in sit catalyst modification with catechol, creating catecholo-Ru(bpy $)_{2}(\text { Cat6 })^{30}$ was ruled out because it did not promote alkylation with or without the addition of exogenous catechol. $\mathbf{e}$, In situ formation of a reactive boronic acid catechol ester is suggested. f, 1-Propylboronic acid catechol ester and 4-bromobutylboronic acid catechol ester were successfully added without the addition of exogenous catechol. This suggests that the formation of the catechol ester lowers the $E_{\text {ox }}$ value of the substrate to a range accessible by $\mathbf{C a t} 1\left({ }^{*} E_{\text {ox }}=+0.77 \mathrm{~V}\right)$. $\mathbf{g}$, Voltammetric response of $1 \mathrm{mM}$ catechol in the presence of increasing concentrations of 4 bromobutylboronic acid (black, $0 \mathrm{mM}$; brown, $3 \mathrm{mM}$; green, $6 \mathrm{mM}$; blue, $12 \mathrm{mM}$; red,

$24 \mathrm{mM}$ ) at a glassy carbon macroelectrode in $50 \mathrm{mM}$ phosphate buffer $(\mathrm{pH} 6)$ recorded at $100 \mathrm{mV} \mathrm{s}^{-1} \cdot \mathbf{h}$, Voltammetric response of catechol only ( $1 \mathrm{mM}$; black), 4-bromobutylboronic acid (12 mM; blue), and 4-bromobutylboronic acid in the presence of catechol $(12 \mathrm{mM}$ and $1 \mathrm{mM}$, respectively; red) recorded at $100 \mathrm{mV} \mathrm{s}^{-1}$. i, Simulated voltammetric response for the oxidation of 4-bromobutylboronic acid $(12 \mathrm{mM})$ in the presence of catechol $(1 \mathrm{mM})$ at $100 \mathrm{mV} \mathrm{s}^{-1}$, following the simplified mechanism outlined in $\mathbf{e}$. The simulation highlights the $100 \mathrm{nV}^{-1}$, fllowing importance of the oxidation of he bornic acid ester being catalytic and leading to the reformation of the radical ester has been set at either $1 \times 1 \mathrm{~s}^{-1}$ or $0 \mathrm{~s}^{-1}$ (blue and red, respectively). If the oxidation of the boronic acid ester is not catalytic, no peak is predicted to be voltammetrically observable at $>1 \mathrm{~V}$ versus a saturated calomel reference electrode (SCE). $\mathbf{j}$, Voltammetric response of 4-bromobutylboronic acid $(12 \mathrm{mM})$ in the presence of catechol $(1 \mathrm{mM})$ in $50 \mathrm{mM}$ phosphate buffer $(\mathrm{pH} 6)$ as a function of scan rate $\left(25-400 \mathrm{mV} \mathrm{s}^{-1}\right) . \mathbf{k}, \mathbf{l}$, Voltammetric response of preformed 4-bromobutylboronic acid catechol ester $(1 \mathrm{mM})(\mathbf{k})$ and catechol $(1 \mathrm{mM})$ in $50 \mathrm{mM}$ phosphate buffer $(\mathrm{pH} 6)(\mathrm{I})$ as a function of scan rate $\left(25-400 \mathrm{mV} \mathrm{s}^{-1}\right)$. 


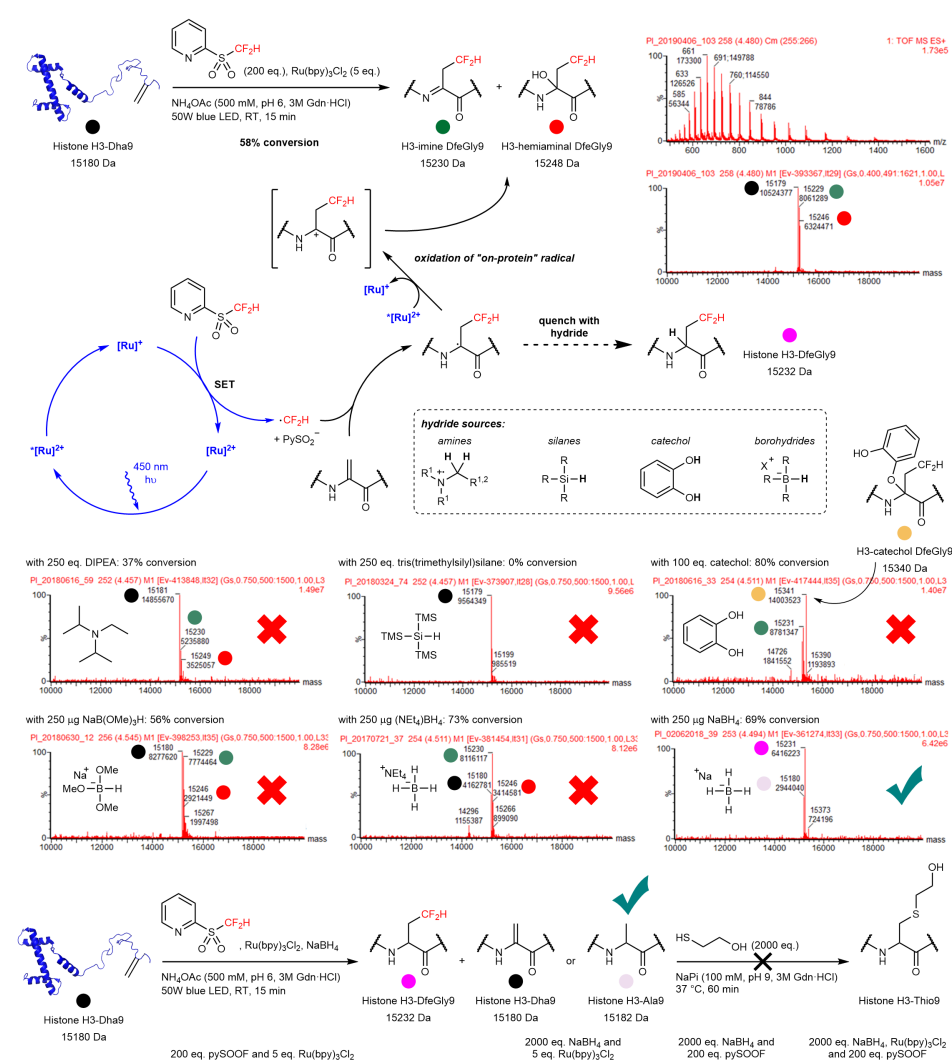

Extended Data Fig. 5 | Initial experiments without iron using various hydride sources, and optimization study with sodium borohydride for pySOOF. a, The formation of oxidative-derived side products H3-imine-DfeGly9 and H3-hemiaminal-DfeGly9 was

detected in an initial, additive-free, light-driven protein-modification reaction with pySOOF and $\mathrm{Ru}(\mathrm{bpy})_{3} \mathrm{Cl}_{2}$. On the basis of this observation a mechanism was postulated, in which the on-protein radical intermediate is oxidized by the excited state of the photocatalyst. To avoid this reaction pathway, the use of hydride donors such as silanes, tertiary amines or

borohydrides were assumed to favour the formation of DfeGly-modified histone at site 9. b, Inferior results were observed when 250 equiv. DIPEA, TTMS and catechol (100 equiv.) were used (with 200 equiv. pySOOF and 5 equiv. Ru(bpy)s) (Supplementary Tables 8,11 , 12). For catechol, excellent conversion efficiencies were observed; however, a catecholDfeGly-modified histone was detected as a major side product. Borohydrides such as

$\mathrm{Na}(\mathrm{OMe})_{3} \mathrm{BH}(0.25 \mathrm{mg})$ and $\mathrm{NEt}_{4} \mathrm{BH}_{4}(0.25 \mathrm{mg})$ showed promising reactivity, but only the oxidation-derived side products were formed. Only with sodium borohydride was the desired DfeGly-modified histone formed in moderate conversion (Supplementary Table 8). c, Reduction of Dha to Ala by $\mathrm{NaBH}_{4}$ was identified as a potential limitation for the $\mathrm{NaBH}_{4}$ mediated reaction. To test this undesired pathway, a crude reaction mixture was bufferexchanged to $\mathrm{NaPi}(100 \mathrm{mM}, \mathrm{pH} 9,3 \mathrm{M} \mathrm{GdnHCl})$ and incubated with a large excess of 2 mercaptoethanol. After $1 \mathrm{~h}$ at $37^{\circ} \mathrm{C}$, no formation of the corresponding thiol-Michael protein adduct was detected, proving Ala form tion. The $100 \%$ stacked bar graph $(n=1$, with ing with single dat warize the results of the optimization stulles of the $\mathrm{NaBH}_{4}$ - of the cod photochen different concention

(Supplementary Tables 9, 10). Less than 500 equiv. NaBH4 resultud in the formation of

undesired oxidative side products. Increasing the reagent concentration, photocatalyst loading or reaction times did not improve the reaction. $\mathbf{d}$, Lower temperature increased the conversion, most probably by slowing down the reduction of Dha by $\mathrm{NaBH}_{4}$.

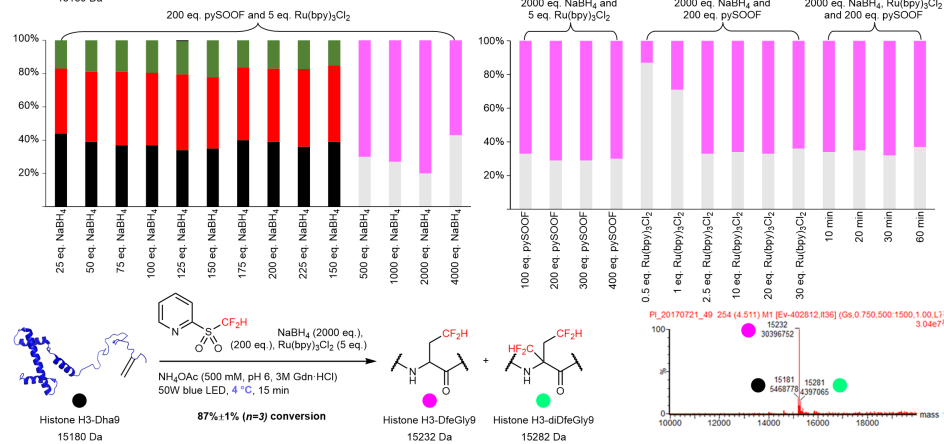



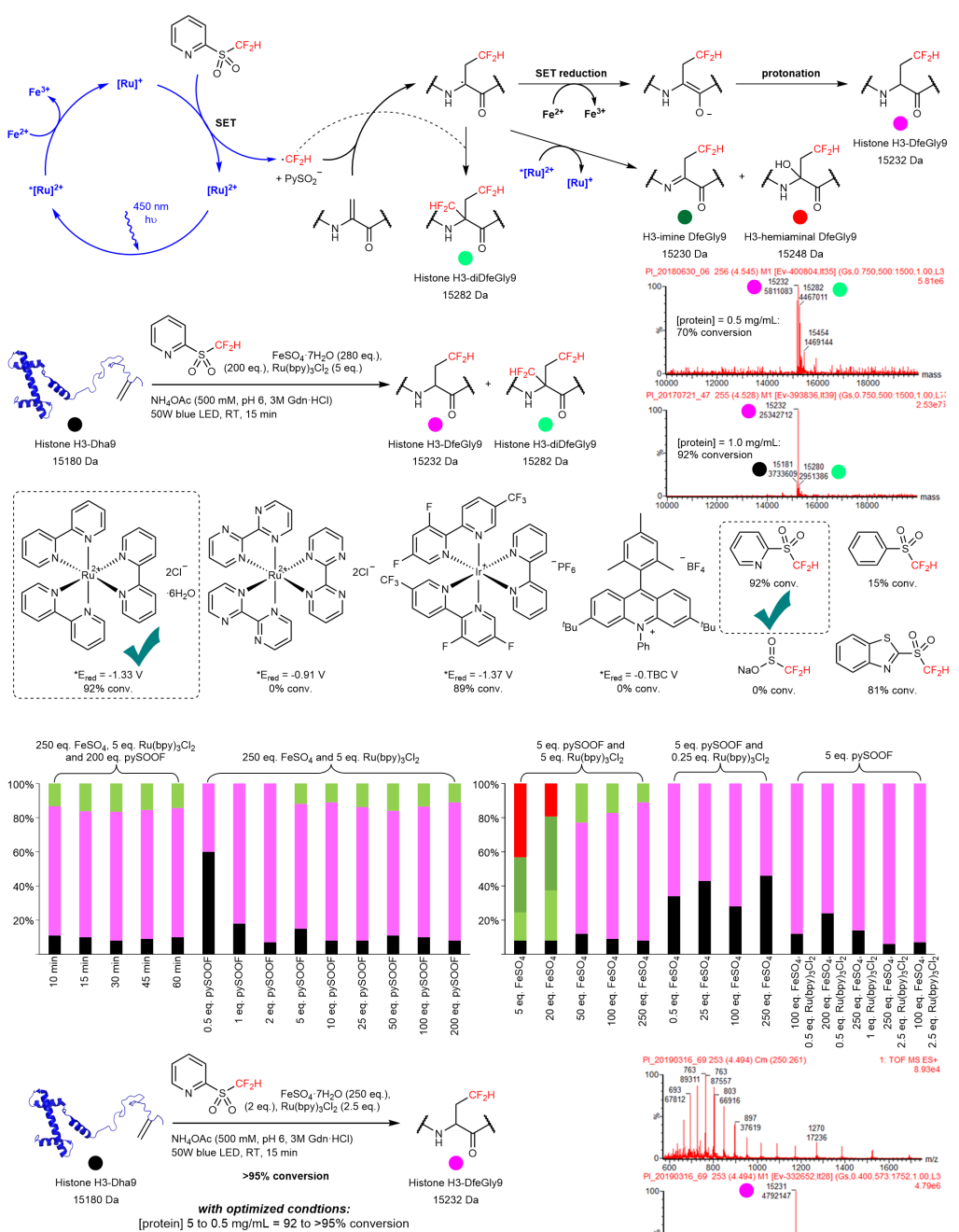

Extended Data Fig. 6 | Optimization study of Fe(II)-mediated protein modification reaction with pySOOF. a, In the photochemical modification reaction with pySOOF, $\mathrm{Fe}$ (II) acts as a reductive quencher for the photoredox cycle and as a single-electron reductant of the on-protein radical intermediate forming the enolate intermediate. However, side products,

such as $\mathrm{H} 3$-imine-DfeGly9, H3-hemiaminal-DfeGly9 or H3-diDfeGly9, could be generat
because of inefficient quenching of the on-protein radical intermediate. b, In an initial

because of inefficient quenching of the on-protein radical intermediate. $\mathbf{b}$, In an initial experiment with 200 equiv. pySOOF, 280 equiv. $\mathrm{FeSO}_{4}, 5$ equiv. $\mathrm{Ru}(\mathrm{bpy})_{3} \mathrm{Cl}_{2}$ and $66 \mu \mathrm{M}$
histone $\mathrm{H} 3$-Dha9 with a protein concentration of $0.5 \mathrm{mg} \mathrm{ml}^{-1}, 70 \%$ conversion to a mixture histone $\mathrm{H} 3$-Dha9 with a protein concentration of $0.5 \mathrm{mg} \mathrm{ml}^{-1}, 70 \%$ conversion to a mixture of $\mathrm{H} 3-\mathrm{DfeGly} 9$ and $\mathrm{H} 3$-diDfeGly (57:43) was observed. The formation of the mono-addition
product was favoured at higher protein concentration $\left(1 \mathrm{mg} \mathrm{ml}^{-1}\right)$ and the conversion was product was favoured at higher protein concentration (1 $\mathrm{mg} \mathrm{ml}$ ) and the conversion was increased to $92 \%$ (Supplementary Table different ${ }^{*} E_{\text {red }}$ values $(-0.56$ to $-1.37 \mathrm{~V}$ ) and radical precursors were tested, and $\mathrm{Ru}(\mathrm{bpy})_{3}$ and pySOOF were identified as the best combination (Supplementary Table 17). d, The $100 \%$ stacked bar charts $(n=1$, single data values

represented by the $y$-axis span of the corresponding bars) summarize the results of the

optimization studies of the $\mathrm{FeSO}_{4}$-mediated photochemical reaction with different reaction times, concentrations of pySOOF and $\mathrm{FeSO}_{4}$, and catalytic amounts of $\mathrm{Fe}(\mathrm{II})$ and

photocatalyst, respectively (Supplementary Tables 10-15, 18, 20). Short reaction times and pho hevels of rectivity with $<100$ equiv. $\mathrm{FeSO}_{4}$, only oxidation-derived products were cot high levels of indicating the dit

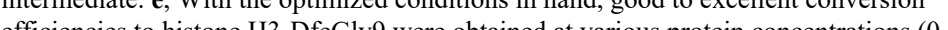
$5 \mathrm{mg} \mathrm{m}^{-1}$ ). SET, single-electron transfer.

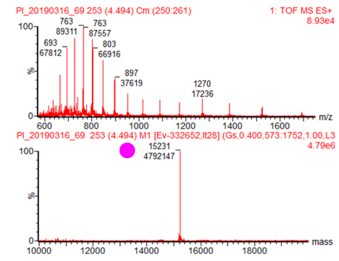




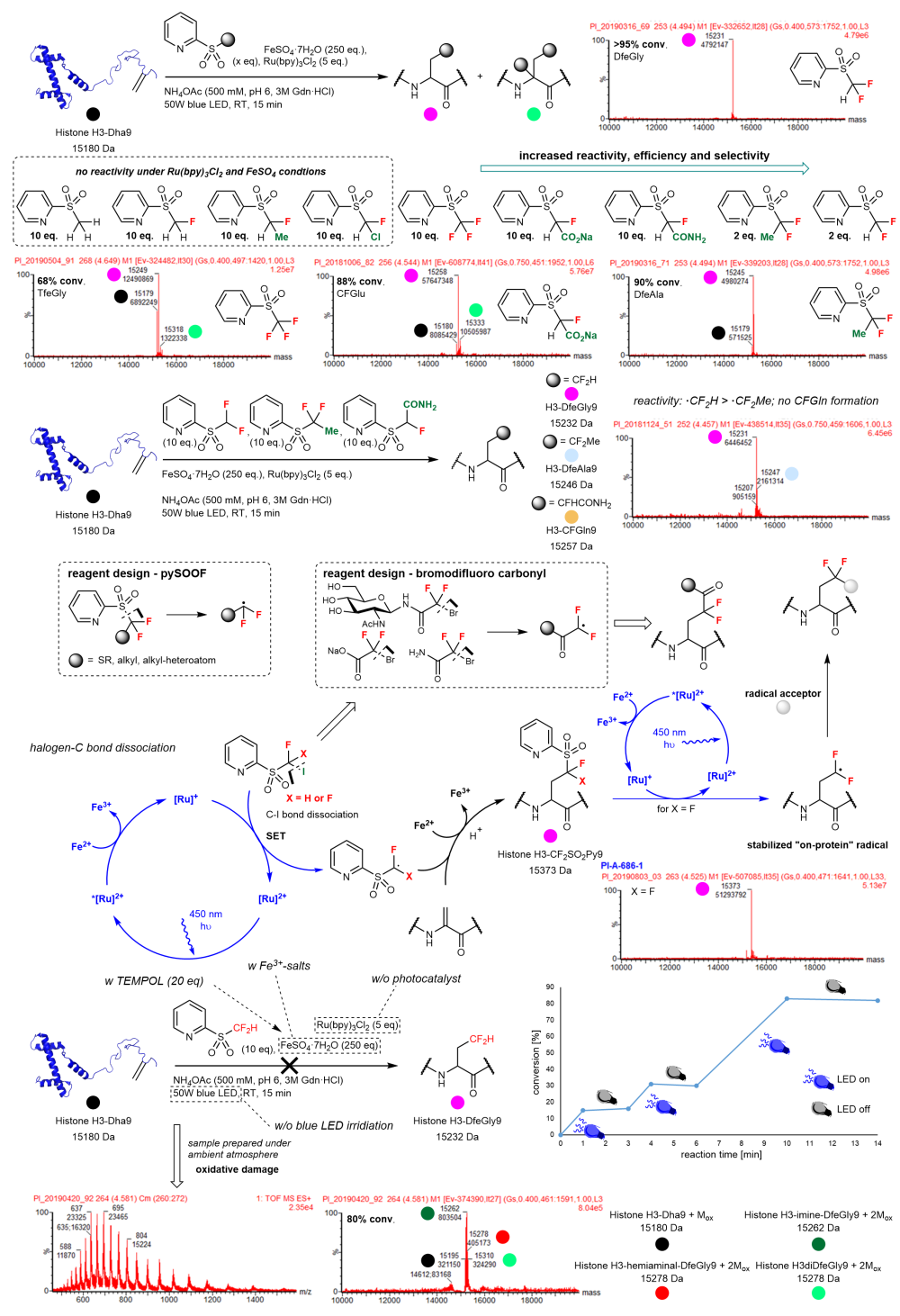

Extended Data Fig. 7 | Investigations on pySOOF reagent reactivity and on-protein mechanism. a, Effect of substituents on the $\alpha$ centre of the created radical on reactivity, efficiency and selectivity (single versus double addition). No reactivity was observed for nonand mono-fluorinated precursors with a $\mathrm{H}, \mathrm{Me}$ or $\mathrm{Cl}$ substituent. With an increase in the electron-withdrawing effect of the additional substituent, radical generation was observed and the resulting products were formed. Moreover, the highest levels of reactivity were observe for ${ }^{\circ} \mathrm{CF}_{2} \mathrm{R}$. $\mathbf{b}$, An equimolar mixture of three pySOOF substrates was applied to the proteinmodification reaction to assess the reactivity order between ${ }^{\circ} \mathrm{CF}_{2} \mathrm{H},{ }^{\circ} \mathrm{CF}_{2} \mathrm{Me}$ and

${ }^{\circ} \mathrm{CFHCONH}{ }_{2}$. During this competition experiment, the reactivity trend ${ }^{\circ} \mathrm{CF}_{2} \mathrm{H}>{ }^{\circ} \mathrm{CF}_{2} \mathrm{Me}$ was identified, and no product formation was observed for ${ }^{\circ} \mathrm{CFHCONH}_{2}$. c, On the basis of the reactivity study of various mono- and difluoro-pySOOF reagents, a suitable radical precursor was designed to allow the efficient generation of ${ }^{\circ} \mathrm{CF}_{2} \mathrm{R}$ for the installation of difluorinatedamino acid residues or PTMs. d, With iodo-pySOOF, homolytic bond cleavage between iodine and the carbon centre was induced, and the pySOOF unit was installed on the Dhatagged histone (Supplementary Tables 22-23). After further photoredox activation, a captodative effect stabilized on-protein radical was formed what allowed further on-protein chemical reactions by trapping the radical with various acceptors (Supplementary Tables 24 37). Moreover, the homolytic iodo-carbon bond cleavage inspired the design of bromodifluoro carbonyl-based radical precursors for the installation of $\mathrm{CF}_{2} \mathrm{Gln}$ - or $\mathrm{CF}_{2} \mathrm{Glu}$-derived amino acids. e, Mechanistic studies proved a radical mechanism, as no product formation was observed with TEMPOL. Furthermore, a photocatalytic process was confirmed, as no observed with TEMPOL. Furthermore, a photocatalytic process was confirmed, as no
conversions were detected without a photocatalyst or blue LED irradiation (Supplementary Table 16). On-off experiments showed only product formation during the irradiation period, excluding a radical chain mechanism. Finally, good reactivity ( $80 \%$ conversion) was excluding a radical chain mechanism. Finally, good reactivity $(80 \%$ conversion) was
observed when the sample was prepared under ambient atmosphere; however, high levels of observed when the sample was prepared under ambient atmosphere; however, high levels formed. 


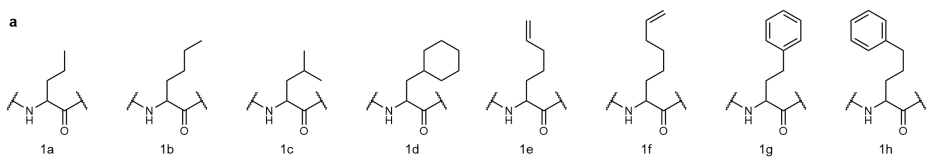
Q. $\int_{1}^{1}$

(15)

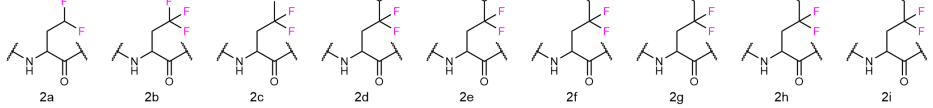

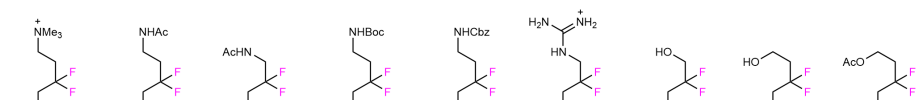

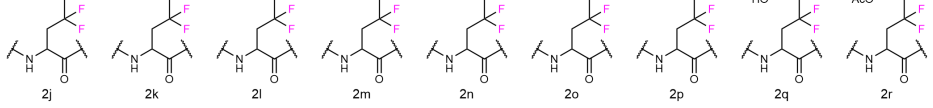

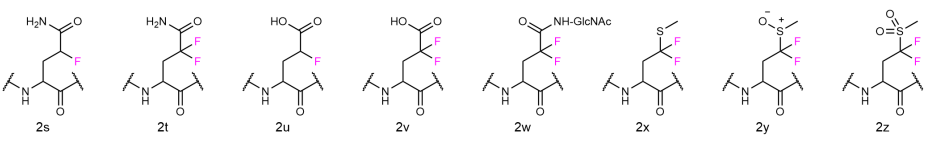

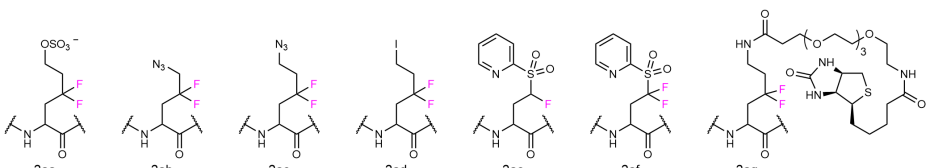

Extended Data Fig. 8 | Substrate scopes for BACED and pySOOF. a, A comprehensive list of all side chains installed into proteins with the BACED reaction manifold. General conditions: protein $1 \mathrm{mg} \mathrm{ml}^{-1} ; 50 \mathrm{~W}, 450 \mathrm{~nm}$ light; $4^{\circ} \mathrm{C}$ to RT; $100-1,500$ equiv. BACED precursor reagent; 10 equiv. Cat1 or Cat2; 100 equiv. catechol; $<6$ ppm $\mathrm{O}_{2} ; \mathrm{pH} 6.0$ buffer $\left(500 \mathrm{mM} \mathrm{NH}_{4} \mathrm{OAc}\right.$ or $\left.\mathrm{PBS} \pm 3 \mathrm{M} \mathrm{Gdn} \cdot \mathrm{HCl}\right) . \mathbf{b}, \mathrm{A}$ comprehensive list of all side chains installed into proteins with the pySOOF reaction manifold. General conditions: protein $1 \mathrm{mg} \mathrm{m}^{-1}$. $50 \mathrm{~W}, 450 \mathrm{~nm}$ light; RT; $2-5$ equiv, pySOOF precuror Cat1; 50-100 equiv. $\mathrm{FeSO}_{4} ;<6 \mathrm{ppm} \mathrm{O}_{2} ; \mathrm{pH}_{6} 6$ buffer $(500 \mathrm{mM} \mathrm{NH} \mathrm{OAc}$ or vaious of buffers).
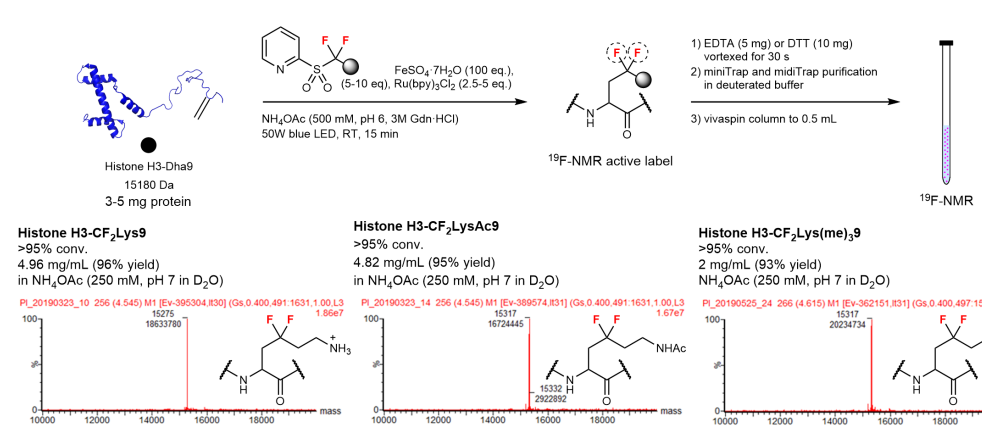

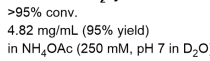

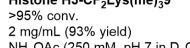

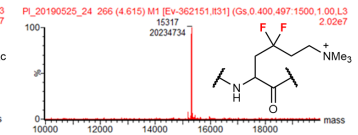

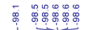

$\stackrel{\circ}{\stackrel{2}{1}}$

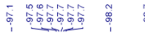

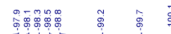

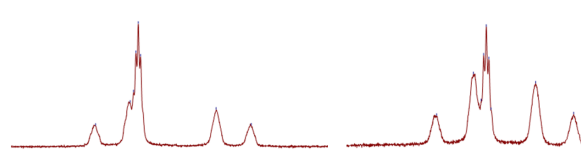

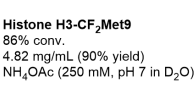

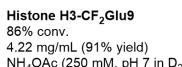
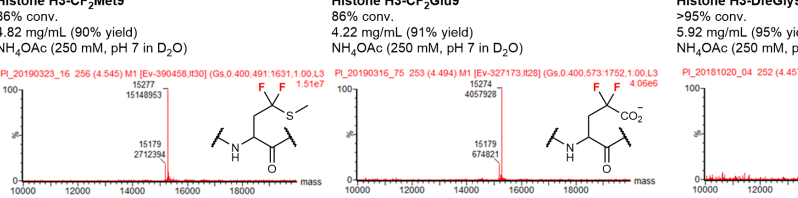

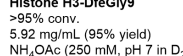

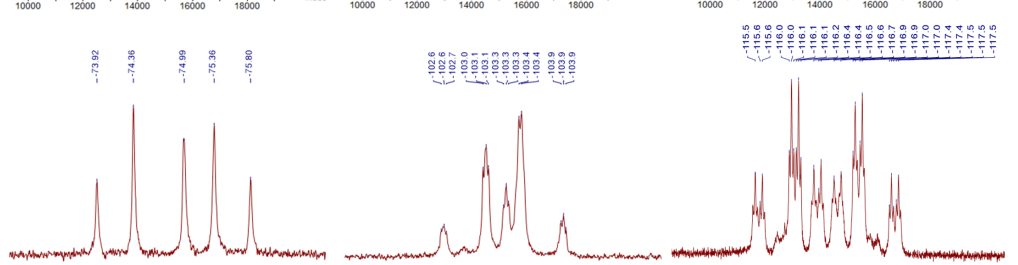

Extended Date Fig. 9 | Upscaling of the protein modification with pySOOF and ${ }^{19} \mathrm{~F}$

NMR analysis. The scalability of protein modification reaction with pySOOF was studied

and high conversion efficiencies were observed for pySOOF-Lys, LysAc, Lys(Me) $)_{3}$, Met,

Glu and DfeGly using 4-6 mot, crude mixture was vithe che deuterace desalting colunis. After puification, excellont yields we (AV600) 


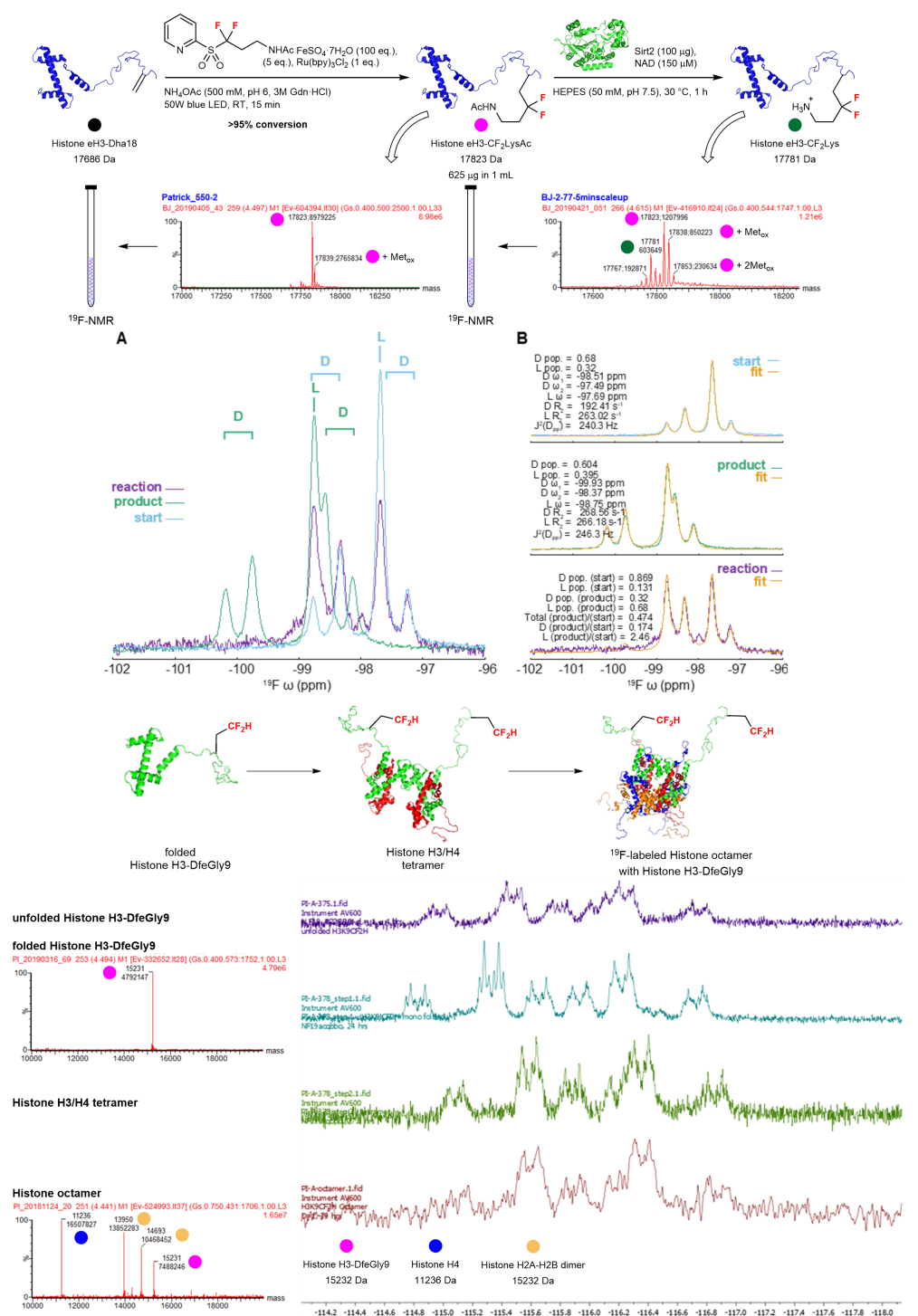

Extended Date Fig. 10 | Application of difluorinated amino acid-labelled proteins in ${ }^{19} \mathrm{~F}$ NMR studies. a, Milligram-scale chemical mutagenesis to generate the substrate histone eH3.1- $\mathrm{CF}_{2}$ LysAc18, in order to investigate deacetylation by Sirt2 by comparing the ${ }^{19} \mathrm{~F}$ NMR analysis of the starting material and after enzymatic reaction. The desired difluoro-labelled analysis of the stanting naterial and after enzynatic reaction. The desired difluoro-labelled histone was formed in excellent conversion, with low levels of Met oxidation. After the deacetylation, histone eH3.1- $\mathrm{CF}_{2} \mathrm{Ly}$ sAc18 and histone eH $3.1-\mathrm{CF}_{2}$ Lys were detected by LCMS, proving that the fluorinated histone was accepted as substrate for Sirt2. b, $\mathbf{c},{ }^{19} \mathrm{~F}$ NMR spectra were acquired for 'start' and 'product' states, as well as when the solution containing start was added to the enzyme Sirt2 (reaction). The spectra of the start and product states consisted of an $A B$ quartet (D) and an apparent singlet state (L). The spectrum of the reaction contained the singlet state of the product and the $\mathrm{AB}$ quartet of the start, suggesting that the singlet state almost completely reacted with Sirt2, whereas the species that gave rise to the $\mathrm{AB}$ quartet did not. To quantify this, the start and product spectra were simulated to determine the relevant resonance frequencies and coupling constants, and the 'reaction' spectrum was simulated by taking the species identified in start and product but with scaled intensities. d, The histone H3-DfeGly9 sample had its ${ }^{19} \mathrm{~F}$ NMR spectra recorded as an unfolded protein species in unfolding buffer $(7 \mathrm{M} \mathrm{GdnHCl}, 10 \mathrm{mM}$ Tris, $1 \mathrm{mM}$ EDTA, $10 \mathrm{mM}$ DTT, $1 \mathrm{mM}$ benzamidine, $\mathrm{pH} 7.5,50 \% \mathrm{D}_{2} \mathrm{O}, 0.1 \mu$ trifluoroethanol internal standard), folded species in Tris buffer ( $150 \mathrm{mM} \mathrm{NaCl}, 10 \mathrm{mM}$ Tris, $1 \mathrm{mM}$ EDTA, $2 \mathrm{mM}$ $\beta \mathrm{ME}, \mathrm{pH} 7.5,50 \% \mathrm{D}_{2} \mathrm{O}, 2 \mathrm{mg} \mathrm{m}^{-1}$ protein, $0.75 \mathrm{ml}, 1 \mu \mathrm{l}$ of $0.1 \%$ trifluoroethanol internal standard), reconstituted histone $\mathrm{H} 3-\mathrm{H} 4$ tetramer in refolding buffer $\left(2.5 \mathrm{mg} \mathrm{ml}^{-1}\right.$ tetramer, standard), reconstituted histone $1 \mathrm{ml}$-H $\mathrm{H} 4$ tetramer in refolding buffer $\left(2.5 \mathrm{mg} \mathrm{m}^{-1}\right.$ tetramer, H2A-H2B-H3-H4 octamer in refolding buffer $\left(1.6 \mathrm{mg} \mathrm{ml}^{-1}\right.$ octamer, $0.5 \mathrm{ml}$ buffer, $50 \% \mathrm{D}_{2} \mathrm{O}$, $0.1 \mu \mathrm{l}$ trifluoroethanol internal standard). All the recorded ${ }^{19} \mathrm{~F}$ NMR spectra were compared and small changes in the chemical shifts were observed. Interestingly, the biggest changes and small changes in the chemical shifts were observed. Interestingly, the biggest changes were detected between the unfolded and folded histone $\mathrm{H} 3$ and after tetramer formation,
potentially owing to changes in tumbling rate. LC-MS analysis of the octamer product potentially owing to changes in tumbling rate. $\mathrm{LC}$
confirmed the presence of all four histone types. 

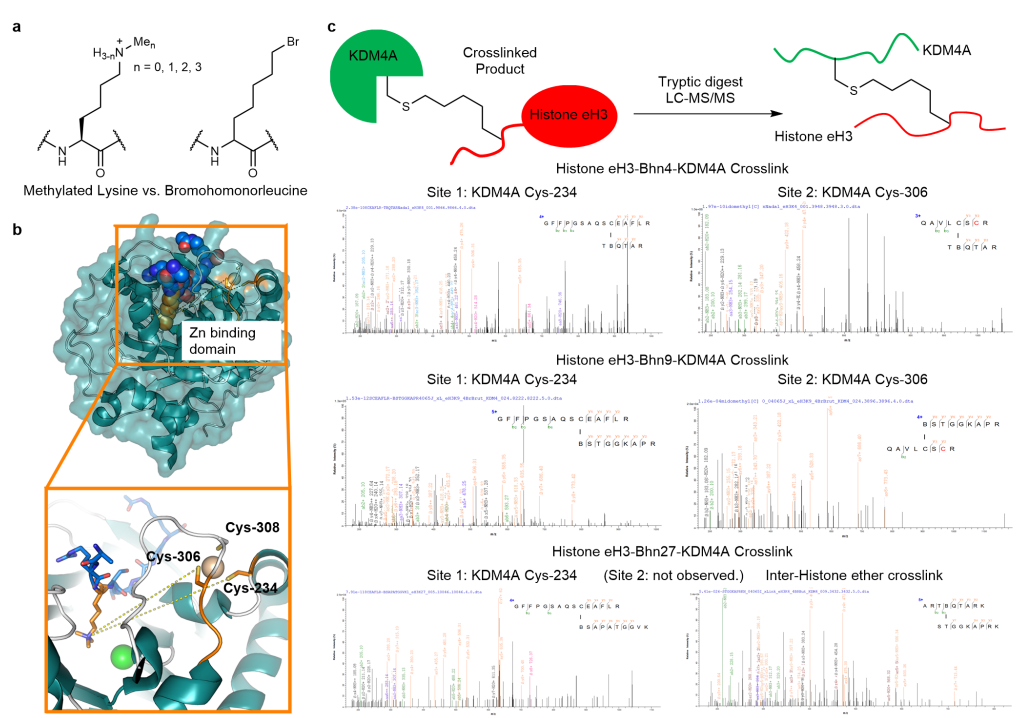

Site 1: KDMAA Cys-234

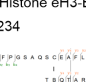

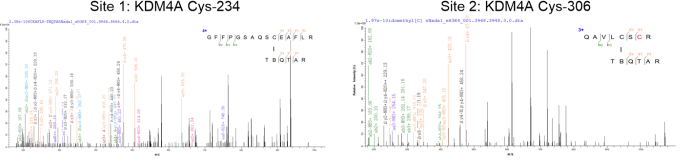

Site 1: KDMAA Cys-234 Histone eH3-Bhng-KDMAA Crosslin

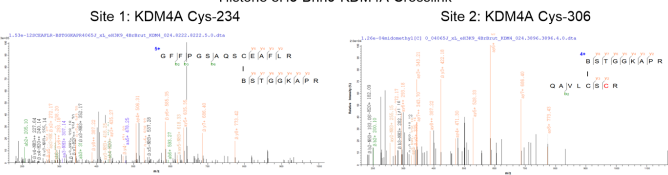

Histone eH3-Bhn27-KDMAA Crosslink
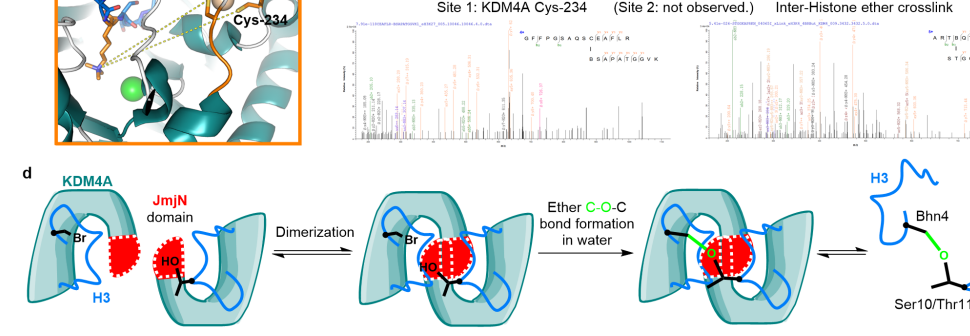

нз $M$
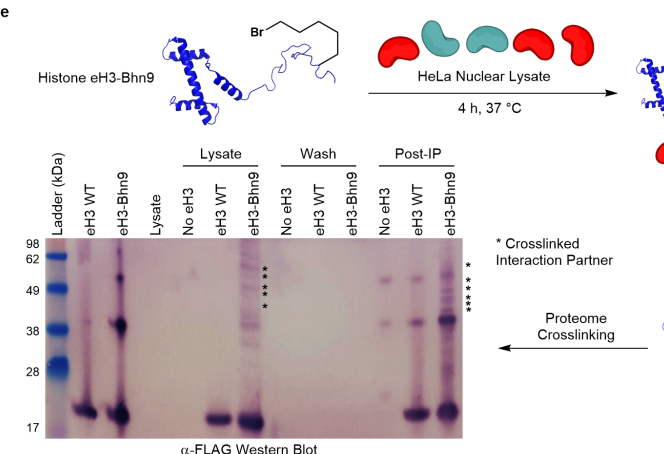

Extended Data Fig. 11 | Effective molarity driven protein-protein crosslinking with electrophile-containing side chains. a, A comparison of the connectivity of a modified lysine side chain (via methylation) and bromohomonorleucine (Bhn, 1u) used for

crosslinking. b. Structure of histone eH3.1-mimicking peptide binding to KDM4A. Identified cysteines that undergo crosslinking (Cys306 and Cys234) are highlighted in orange and their distance to $\mathrm{H} 3-\mathrm{K} 9$ is highlighted. $\mathbf{c}$. Workflow of the crosslinking reaction products and their identification by LC-MS/MS. Representative spectra are shown for each crosslinking site (top, eH3.1-Bhn4; middle, eH3.1-Bhn9; bottom, eH3.1-Bhn27) and captured cysteine residue. The bottom right spectrum shows an inter-histone crosslink via ether formation as found in the in-solution digest. d, Williamson $\mathrm{C}-\mathrm{O}-\mathrm{C}$ bond ether formation in an

intermolecular fashion between $\mathrm{H} 3$ proteins (Bhn4 in one linked to hydroxyl in another) is driven by effective molarity, possibly suggesting a transient dimer model for KDM4A function. e, The histone eH3.1-Bhn9 alkylator protein was incubated with HeLa nuclear lysate to capture interaction partners via promixity-driven crosslinking. After enrichment via the HA tag (on histone eH3.1), an $\alpha$-FLAG western blot reveals multiple higher MW bands corresponding to the mass of the histone plus that of the captured interaction partner. No higher MW bands were seen in conditions lacking Bhn. 